\title{
Solar wind Alfvén waves: a source of pulsed ionospheric convection and atmospheric gravity waves
}

\author{
P. Prikryl ${ }^{1}$, D. B. Muldrew ${ }^{1}$, G. J. Sofko ${ }^{2}$, and J. M. Ruohoniemi ${ }^{3}$ \\ ${ }^{1}$ Communications Research Centre, Ottawa, ON, Canada \\ ${ }^{2}$ University of Saskatchewan, Saskatoon, Canada \\ ${ }^{3}$ The Johns Hopkins University Applied Physics Laboratory, Laurel, MD, USA
}

Received: 30 March 2004 - Revised: 19 November 2004 - Accepted: 6 December 2004 - Published: 28 February 2005

\begin{abstract}
A case study of medium-scale travelling ionospheric disturbances (TIDs) that are correlated with solar wind Alfvén waves is presented. The HF radar groundscatter signatures of TIDs caused by atmospheric gravity waves with periods of $20-40 \mathrm{~min}$ are traced to a source at high latitudes, namely pulsed ionospheric flows (PIFs) due to bursts in the convection electric field and/or the associated ionospheric current fluctuations inferred from ground magnetic field perturbations. The significance of PIFs and TIDs in the context of solar-terrestrial interaction is that Alfvénic fluctuations of the interplanetary magnetic field (IMF) observed in the solar wind plasma streaming from a coronal hole correlate with PIFs and TIDs. The link between the solar wind Alfvén waves and TIDs is corroborated by the ground magnetic field signatures of ionospheric current fluctuations that are associated with the IMF- $B_{y}$ oscillations and TIDs. The observed PIFs and the associated negative-topositive deflections of the ground magnetic field X component are interpreted as ionospheric signatures of magnetic reconnection pulsed by solar wind Alfvén waves at the dayside magnetopause. Although the clarity of the radar lineof-sight velocity data may have been affected by anomalous HF propagation due to intervening TIDs, the application of a pure state filtering technique to analyze the radar data time series reveals a one-to-one correspondence between PIFs, TIDs and solar wind Alfvén waves. The spectra of solar wind and ground magnetic field perturbations are similar to those of PIFs and TIDs. The ground-scatter signatures indicate TID wavelengths, phase velocities and travel times that are consistent with ray tracing, which shows a subset of possible gravity wave group paths that reach the F region from a source in the E region after the wave energy first travel downward to the upper mesosphere where the waves are reflected upward. The observed one-to-one correspondence between the convection electric field bursts and TIDs is consistent with the modeling results for large-scale TIDs by Millward et al. (1993a,b). The correlation with solar wind Alfvén waves
\end{abstract}

Correspondence to: P. Prikryl

(paul.prikryl@crc.ca) points to very direct coupling of energy in the solar wind into the subauroral atmosphere.

Key words. Magnetospheric physics (Solar windmagnetosphere interactions) - Ionosphere (Ionosphereatmosphere interactions) - Meteorology and atmospheric dynamics (Waves and tides)

\section{Introduction}

In his seminal paper on the existence of a new kind of wave, namely electromagnetic-hydrodynamic waves, Alfvén (1942) foresaw their importance in solar physics. They are now universally recognized as one of three distinct wave modes of magneto-hydrodynamic (MHD) plasma waves, the Alfvén (intermediate) mode, and the fast and slow magnetoacoustic modes. In a collisionless plasma the Alfvén waves propagate essentially undamped and have been observed in the solar corona (Hollweg et al., 1982). Quasi-periodic fluctuations of the interplanetary magnetic field (IMF) and ion velocity components that are indicative of Alfvén waves are common in the solar wind (Belcher and Davis, 1971; Tsurutani et al., 1990), particularly in highspeed plasma streams from coronal holes.

The solar wind Alfvén waves interact with and are transmitted across the bow shock (McKenzie and Westphal, 1969; Hassam, 1978; Sibeck et al., 1997; Walker, 2002). They generate pressure pulses (Yan and Lee, 1996; Lin et al., 1996) in the magnetosheath that stimulate the magnetosphere, resulting in geomagnetic pulsations and pulsed ionospheric convection/currents. Interplanetary Alfvén wave trains were identified as a source of high intensity, long-duration, continuous auroral activity events (Tsurutani and Gonzales, 1987; Tsurutani et al., 1990). When the IMF $B_{z}$ component is negative (southward), solar wind Alfvén waves are effective in modulating dayside solar wind-magnetosphere coupling through pulsed magnetic reconnection. This results in pulsed ionospheric flows (PIFs) (Prikryl et al., 2002) and associated cusp particle signatures (Rae et al., 2004) which, in turn, 
structure the ionospheric density into polar patches (Prikryl et al., 1999). Also, a number of authors (e.g. Potemra et al., 1989; Prikryl et al., 1998; Kepko et al., 2002; Stephenson and Walker, 2002; Walker, 2002) have shown solar wind MHD waves as direct drivers of magnetospheric pulsations.

In this paper, it is shown that, through the coupling to the magnetosphere-ionosphere-atmosphere system, solar wind Alfvén waves generate atmospheric gravity waves (AGWs) and their ionospheric signatures - travelling ionospheric disturbances (TIDs). Theoretical understanding of AGWs and their role in the ionosphere was developed by Hines (1960) and ionospheric sources of gravity waves have been recognized (Chimonas and Hines, 1970; Chimonas, 1970; Testud, 1970; Richmond, 1978). Also, a causal relationship between the AGWs generated in the auroral zone (by Joule heating, Lorentz force or particle precipitation) and TIDs has been well established (see, e.g. Hocke and Schlegel (1996) and the references therein). The Worldwide Atmospheric Gravity-wave Studies (WAGS) program (see, e.g. Crowley and Williams, 1987; Williams et al., 1993) clearly demonstrated that large-scale TIDs observed at mid-latitudes originate in the auroral oval. The observed characteristic periods of TIDs (typically 30-70 min) are well correlated with auroral variations (electric field and Joule heating) of similar periods. On the other hand, auroral fluctuations with time scales of $20 \mathrm{~min}$ or less are strongly attenuated in the observed TIDs. Thus, the auroral plasma convection, which commonly exhibits quasi-periodic, recurrent bursts (e.g. Williams et al., 1992), is a likely source of gravity waves. Such a source then determines not only the magnitude but also the period of the gravity waves (Crowley and Williams, 1987). Millward et al. (1993a,b) modeled gravity waves generated by enhancements in the ionospheric electric field. Each electric field enhancement caused a Joule heating pulse, which, in turn, launched a single gravity wave propagating equatorward and poleward of the source region.

Direct and Earth-reflected gravity waves were theoretically described and distinguished by Francis (1974), who pointed out that the latter appear in the $\mathrm{F}$ region as wave packets (a number of nearly monochromatic wave cycles) while the former induce isolated (nonperiodic) TIDs, consistent with the results by Millward et al. (1993a,b). Francis et al. (1974) also suggested a dominance of upperatmospheric (as opposed to tropospheric) sources of gravity waves. Radar backscatter sounding techniques for observation of motions of large-scale F-region irregularities date back to the 1950s (Tveten, 1961 and references therein). Hunsucker and Tveten (1967) used the HF backscatter technique to observe large-scale TIDs on ground-scatter records. At the ionospheric reflection point the signals were modulated (focused/defocused) by TIDs which the latter authors attributed to imperfectly ducted atmospheric gravity waves generated by auroral sources. More recently, HF radars were used to observe ionospherically generated mediumscale gravity waves, which may be Earth-reflected and then produce trains of TIDs, many hundreds of kilometers equatorward of the original source region (Samson et al., 1989,
1990). These radars are now a part of SuperDARN (Super Dual Auroral Radar Network) (Greenwald et al., 1995). SuperDARN has become very useful for the study of TIDs (Bristow et al., 1994) because of the large spatial coverage of the auroral and polar regions, which are known to be an important source of TIDs. Subsequent SuperDARN work on TIDs pursued studies of the relationship between auroral electrojet currents and TIDs observed by SuperDARN (Sofko and Huang, 2000; Huang et al., 1998a,b) but also addressed the question of how one can deduce TID properties from SuperDARN ground-scatter (Hall et al., 1999; Stocker et al., 2000; MacDougall et al., 2001). In particular, the last named authors showed that the assumption that a TID is located at approximately half the range of the radar groundscatter intensification, the intensification due to focusing by TIDs, may be valid only for low amplitude TIDs. Such an assumption that has been used in earlier SuperDARN studies of TIDs implies that the TID horizontal phase velocity would be about half of the observed time rate of change of the distance to the ground backscatter intensification. This assumption of the factor 0.5 for making TID horizontal phase velocity estimations was challenged by Hall et al. (1999), who suggested that a more suitable value is 0.6 . Further HF ray-tracing analysis and modeling of TIDs by MacDougall et al. (2001) concluded that, depending on the TID amplitude, the appropriate proportionality factor may actually be close to 1.0 , which almost doubles the horizontal TID phase velocities and wavelengths derived from the SuperDARN ground-scatter signatures of TIDs.

While the large-scale TIDs have been attributed to auroral electrojet surges the identification of sources of mediumscale TIDs has remained difficult. Both the auroral activity (e.g. Hunsucker, 1982, Lewis et al., 1996; Oyama et al., 2001) and tropospheric weather disturbances (e.g. Bertin et al., 1975; Waldock and Jones, 1987; Oliver et al., 1997) can generate medium-scale AGWs, particularly for TIDs that are observed at middle latitudes. At high latitudes, Samson et al. (1990) suggested that the AGWs observed by SuperDARN originate near the ionospheric convection reversal boundary. Thus, it has been hypothesized that the IMF variations that lead to auroral electrojet fluctuations generate AGWs/TIDs, but the actual identification of the distant sources of the observed TIDs has posed difficulties in spite of the use of various observation techniques (Lewis et al., 1996; MacDougall et al., 1997; Hall et al., 1999, Oyama et al., 2001). One of the advantages of SuperDARN for the study of gravity waves is that it allows simultaneous observations of TIDs and of their high-latitude source activity. Various HF propagation modes frequently result in observations of the TID modulated ground-scatter along with the ionospheric echoes at ranges immediately poleward of the ground-scatter (Huang et al., 1998a; Sofko and Huang, 2000). A causality sequence of relationship among the IMF southward turnings, auroral electrojet currents, and gravity waves was reported for a case study (Huang et al., 1998b). The proximity of the observed TID signatures to the source region (auroral electrojet) indicated direct rather than ducted or Earth-reflected 
gravity waves. Sofko and Huang (2000) associated each of the 100-min pulses observed in the ionospheric flow (electric field), the IMF and ground magnetic field with a pair of gravity waves (two wave pulses). For the time intervals presented in the latter three studies, we note that the IMF and solar wind plasma velocity components were highly correlated, which is a characteristic of solar wind Alfvén waves.

Here we present a case study (Sect. 4) showing that Alfvénic fluctuations in the solar wind cause the ionospheric convection to pulse, thereby generating AGWs and TIDs. In Sect. 3, we present results of ray tracing of AGWs in a model atmosphere from an assumed source at the E-region altitude. These results suggest that the observed TIDs can be explained by AGWs that reach F-region altitudes after being reflected by the temperature gradient in the upper mesosphere. In Sect. 5, we discuss the results pointing to solar wind MHD wave forcing in the upper atmosphere.

\section{Instruments and techniques}

SuperDARN is an international network of coherentbackscatter HF radars primarily designed to monitor ionospheric convection and thus the convection electric field (Greenwald et al., 1995). These frequency-agile (8-20 MHz) radars are single beam radars in which a phasing matrix is used to sweep the beam through 16 successive positions with azimuthal separation of $3.24^{\circ}$. Each beam is gated into 75 range cells which are $45 \mathrm{~km}$ long in standard operations. Normally, the dwell time for each beam position is $7 \mathrm{~s}$, giving a full 16-beam scan that covers $52^{\circ}$ in azimuth every $2 \mathrm{~min}$. Several parameters, including the line-of-sight (LOS) Doppler velocity, spectral width and backscatter power from ionospheric plasma irregularities, are routinely measured. In the standard mode the two line-of-sight velocities measured at the intersection of the beams from two radars can be combined to provide convection velocity perpendicular to the magnetic field. Global ionospheric convection and potential maps are derived by fitting the available velocity data to an expansion of the potential in terms of spherical harmonic functions (Ruohoniemi and Baker, 1998). Supplemental data from a statistical convection model are included to constrain the solution over areas with no radar coverage. Ionospheric-source gravity wave signatures can be identified in the ground-scatter power that is modulated due to focusing/defocusing of the HF signal by the gravity-wave-induced undulations of the lower F region of the ionosphere (Samson et al., 1989).

Ground-based magnetometers provide magnetic field signatures of ionospheric currents to support the SuperDARN data. High-latitude magnetometer data were obtained at $\mathrm{Ny}$ Åleslund and Longyearbyen on Svalbard, a part of the Scandinavian IMAGE array (Viljanen and Häkkinen, 1997). Figure 1 shows the Northern Hemisphere SuperDARN radar field-of-view, the Hankasalmi radar beam 13 and the magnetometer sites. The solar wind plasma and magnetic field data are collected by the following satellites: ACE (McCo-

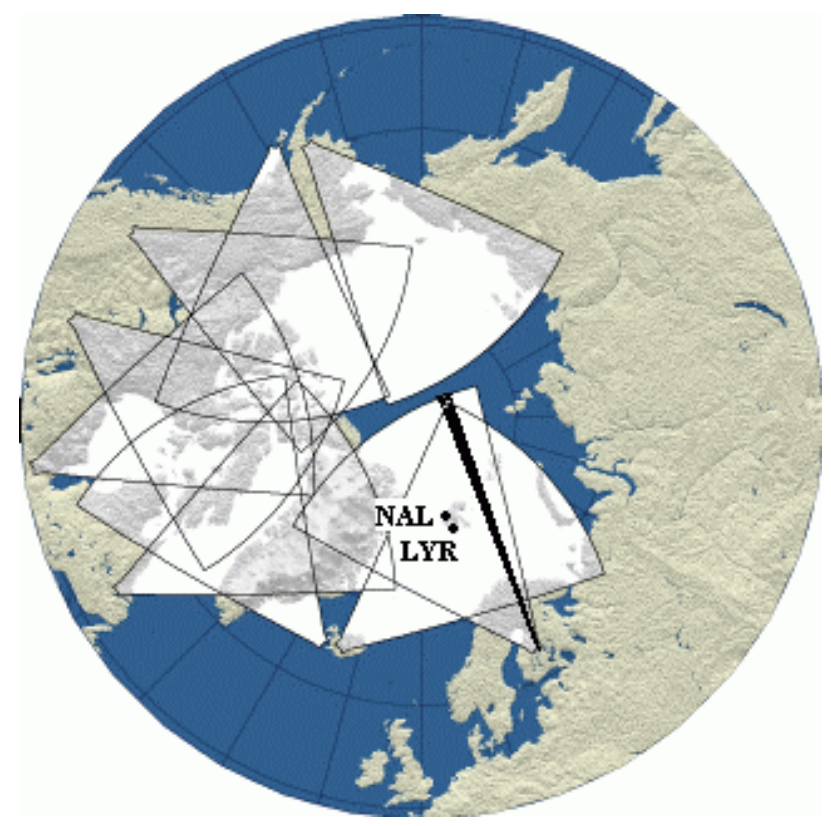

Fig. 1. Northern Hemisphere SuperDARN. The Hankasalmi radar beam 13 and a magnetometer sites at Ny Åleslund (NAL) and Longyearbyen (LYR) are shown.

mas et al., 1998; Stone et al., 1998; Smith et al., 1998), IMP 8 (King, 1982) and WIND (Ogilvie and Parks, 1996). A purestate filtering technique (Samson, 1983) is used to process the radar data time series.

\section{Ray tracing of gravity waves}

Yeh and Liu (1974) reviewed propagation of AGWs in a realistic atmosphere using the ray theory approach and the WKB approximation. They pointed out that a simplified ray-tracing procedure based on Snell's law is applicable for a horizontally stratified atmosphere. Assuming that the sources of gravity waves are quasi-periodic convection/current pulses in the auroral and polar ionosphere, a two-dimensional ray tracing of the gravity waves is conducted. Snell's law for a spherically stratified atmosphere with no horizontal gradients (Muldrew, 1959) is given by $n r \sin \beta=$ constant, where $n$ is the refractive index, $r$ is the distance from the centre of the Earth to a point on the ray and $\beta$ is the angle of incidence. The dispersion relation between the gravity wave frequency $\omega$ and wave vector $\mathbf{k}$ given by Hines (1960) is used:

$\left(\omega^{2}-\omega_{a}^{2}\right) \omega^{2} / C^{2}-\omega^{2}\left(k_{x}^{2}+k_{z}^{2}\right)+\omega_{b}^{2} k_{x}^{2}=0$,

where $\omega_{a}=\gamma \mathrm{g} / 2 \mathrm{C}$ is the acoustic cutoff frequency, $\gamma, C, \mathrm{~g}$ are ratio of specific heats, speed of sound, and acceleration due to gravity, respectively, $k_{x}$ and $k_{z}$ are the horizontal and vertical components of the wave vector $\mathbf{k}$. For a nonisothermal atmosphere (one in which the atmospheric scale height varies with altitude) the Brunt-Väisälä (buoyancy) frequency $\omega_{b}$ is defined as

$\omega_{b}^{2}=(\gamma-1) g^{2} / C^{2}+\left(g / C^{2}\right)\left(d C^{2} / d z\right)$. 

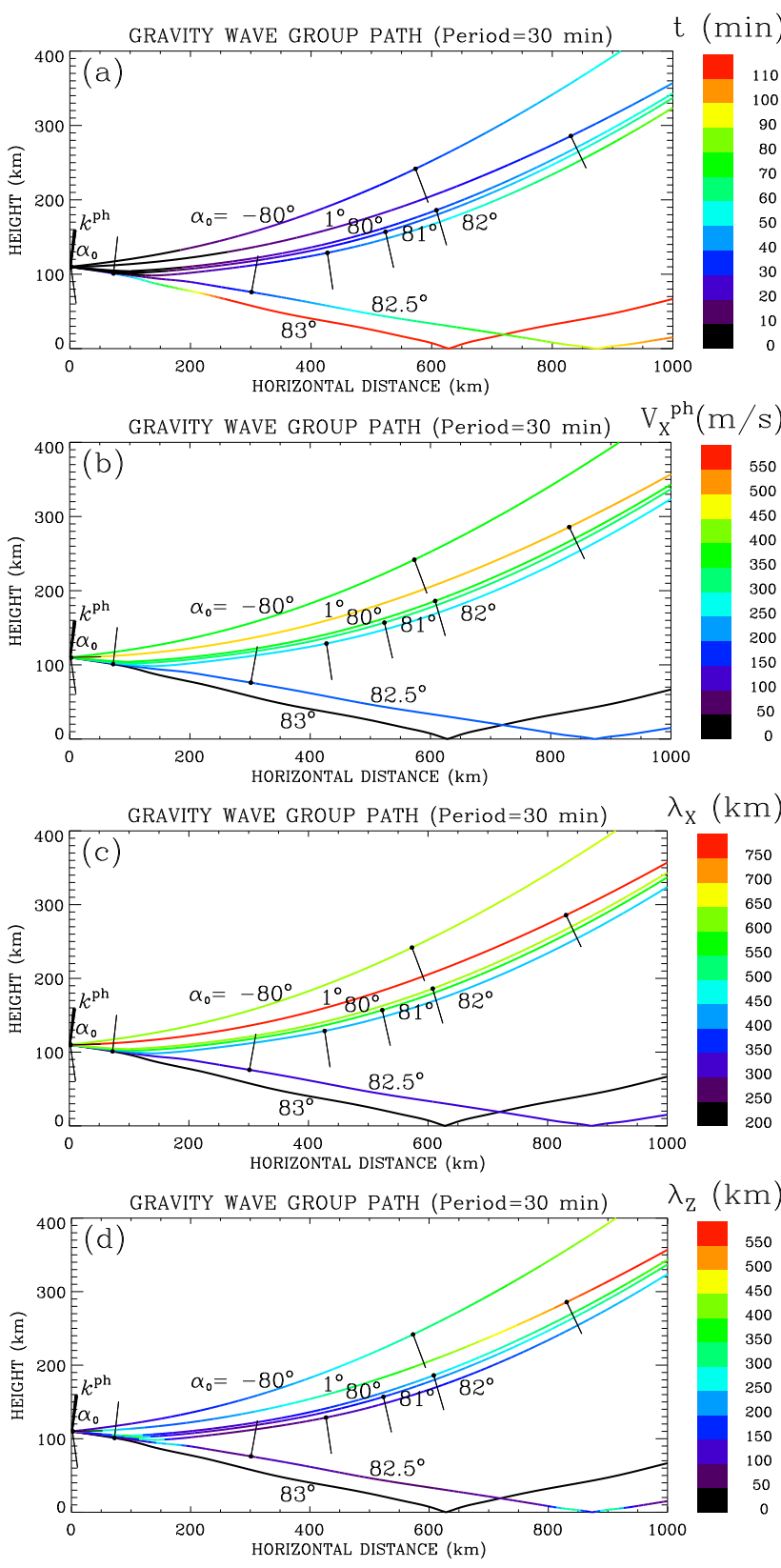

Fig. 2. Ray paths for 30-min period gravity waves in a stationary atmosphere. When the phase propagation direction $k^{p h}$ is upward $\left(\alpha_{0}>0\right)$ the group velocity is downward and vice versa. The rays are the same in all panels, but are colour-coded for time of travel, horizontal wavelength and horizontal phase velocity.

The atmosphere is divided into horizontal slabs of constant temperature and density that are obtained from the MSIS90 model (Hedin, 1991). Viscosity, thermal conductivity and neutral winds are neglected. A typical period of gravity waves observed in the ionosphere by SuperDARN is used. The ray tracing is initiated at an altitude of $110 \mathrm{~km}$ using selected initial values $\alpha_{0}$ of the $\mathbf{k}$ directions $\alpha$, where $\alpha$ is taken to be positive upward from the southward horizontal direction in the Northern Hemisphere. The group velocity
$\mathbf{V}_{g} \equiv\left(\partial \omega / \partial k_{x}, 0, \partial \omega / \partial k_{z}\right)$ or path of energy flow of the gravity wave is obtained from Eq. (1) numerically. We chose $110 \mathrm{~km}$ for the initial height assuming the Lorentz force to be a dominant mechanism of AGW generation. The observed auroral electrojet fluctuations associated with TIDs observed by SuperDARN are generally small, suggesting that Joule heating was less likely to be the source.

Figure 2 shows group paths for gravity waves having a period of $30 \mathrm{~min}$ and originating at an altitude of $110 \mathrm{~km}$ for the MSIS90 model specified for 2 November 1999 (a case study presented in Sect. 4). The rays are the same in all panels but are colour-coded for time of travel, phase velocity, and horizontal and vertical wavelengths. For each ray, the wave vector directions are shown at the start of the ray tracing $\left(\alpha_{0}\right)$ and after one wave period. The time of travel, phase velocity $V_{x}^{p h}$, horizontal $\lambda_{x}$ and vertical $\lambda_{z}$ wavelengths that are shown in Fig. 2 are compared with observations that are discussed later.

For $\alpha_{0} \leq 82^{\circ}$, the ray-traced gravity wave energy reaches the $\mathrm{F}$ region in about an hour or less, either directly $\left(\alpha_{0}<0\right)$ or after being reflected in the upper mesosphere. For $\alpha_{0}<0$ (downward phase velocity), the group direction is upward and the gravity wave energy will escape through the F region over a relatively short horizontal distance less than $1000 \mathrm{~km}$. For $0<\alpha_{0} \leq 82^{\circ}$, the initial group direction is downward but the gravity waves are reflected/refracted by the temperature gradient. After the reflection, the angle $\alpha$ becomes negative (k points downward) and the group direction is upward but still has a large horizontal component. This allows the gravity wave energy to reach the $\mathrm{F}$ region at greater horizontal distances from the source than for the waves whose energy was initially directed upward $\left(\alpha_{0}<0\right)$. For $\alpha_{0}>82^{\circ}$, AGWs reach the ground and are reflected back to the ionosphere.

The horizontal wavelength $\lambda_{x}$ is $>320 \mathrm{~km}$ for the uppermesosphere reflected AGWs, but decreases as the angle $\alpha_{0}$ increases for group paths reaching the ground. Similarly, the horizontal component of phase velocity $V_{x}^{p h}$ is greater than $200 \mathrm{~m} / \mathrm{s}$ for gravity waves reflected in the upper mesophere but decreases for downward directed rays that reach the ground. Because of large phase velocities that are much greater than wind velocities, it is expected that the rays that reach the F region either directly or after reflection in the upper mesosphere will not be significantly affected by neutral winds. The horizontal phase velocity $V_{x}^{p h}$ may become comparable with the neutral wind velocity when $\alpha_{0}$ is larger than $82^{\circ}$, i.e. for the downward group paths that reach the ground, in which case the neutral winds could be important.

The validity of ray tracing near the reflection height, where $1 / k_{z}$ can be greater than the neutral density scale height, is discussed in Appendix A. It is found that although the ray paths may not be valid near reflection, the computed paths are valid a few tens of kilometers above reflection height. For values of $\alpha_{0}<82^{\circ}$ most of the downward propagating energy is reflected in the upper mesosphere (Appendix A).

Bristow et al. (1996) used a dispersion relation they derived from the Navier-Stokes equations with temperature 
gradients included by allowing the scale height to vary with altitude but ignoring viscosity, thermal conductivity and ion drag. For summer atmospheric conditions, they found a reflection layer coinciding with the negative temperature gradient at mesospheric altitudes where $\lambda_{z}$ became imaginary, suggesting that this may then lead to a seasonally dependent reflection of AGWs. Very similar results leading to the same conclusion can be obtained from dispersion Eq. (1) when the scale height variation with altitude is included in Eq. (2). Figure 3 shows examples of the vertical profiles of $\lambda_{z}$ for the same atmospheric model specification that was used for ray tracing (temperature profile is shown) and for AGWs with a 30-min period and horizontal wavelengths $\lambda_{x}=250$ and $350 \mathrm{~km}$. For $\lambda_{x}>320 \mathrm{~km}$, the vertical wavelength becomes purely imaginary below the mesopause in the evanescent layer that is thicker for larger $\lambda_{x}$. If some wave energy tunnels through the evanescent layer to the lower atmosphere, as discussed in Appendix A, these gravity waves could be reflected from the Earth's surface or temperature gradient in the troposphere (Fig. 3).

In summary, ray tracing in a model atmosphere of AGWs generated by an ionospheric source shows three distinct group paths (wave propagation modes) that reach the $\mathrm{F}$ region: rays that travel directly upward, rays that are reflected in the mesosphere, and rays that are reflected in the troposphere or from the Earth's surface. Their basic characteristics are compared with observations in Sects. 4 and 5.

\section{Case study: 2 November 1999}

\subsection{Solar wind Alfvén waves}

The Advanced Composition Explorer (ACE) measured the interplanetary magnetic field (IMF) and various solar wind plasma parameters inside a weakened transitory corotating stream (Burlaga et al., 2001) from a coronal hole that crossed the central solar meridian on 26 October as observed by SOHO. This stream had been observed for two previous solar rotations but, after 2 November (the results discussed here) it dissipated and could not be identified in the ACE data 27 days later. Figure 4 shows hourly averages of the magnetic field magnitude, $|\mathrm{B}|$, solar wind velocity, $V$, and proton density, $n_{p}$. On 31 October within the interaction region (compression ridge) where the faster plasma stream from the coronal hole overtook the slower solar wind, ACE measurements revealed a well-defined stream interface. A sharp increase in the IMF magnitude was associated with a peak in density and rising ion temperature (not shown).

On 1 November after the interaction region had passed ACE, the plasma density dropped below $7 \mathrm{~cm}^{-3}$, the IMF magnitude leveled off at $\sim 6 \mathrm{nT}$ and the solar wind speed in the stream peaked at $\sim 460 \mathrm{~km} / \mathrm{s}$. On 2 November at 06:00 UT, there were three spacecraft in the solar wind. ACE was located at $(220.42,-13.06,-17.75) R_{E}$, IMP 8 was in the prenoon sector at $(29.73,-21.13,-6.30) R_{E}$, and WIND in the predawn sector at $(-18.15,-45.41,-11.74) R_{E}$ in
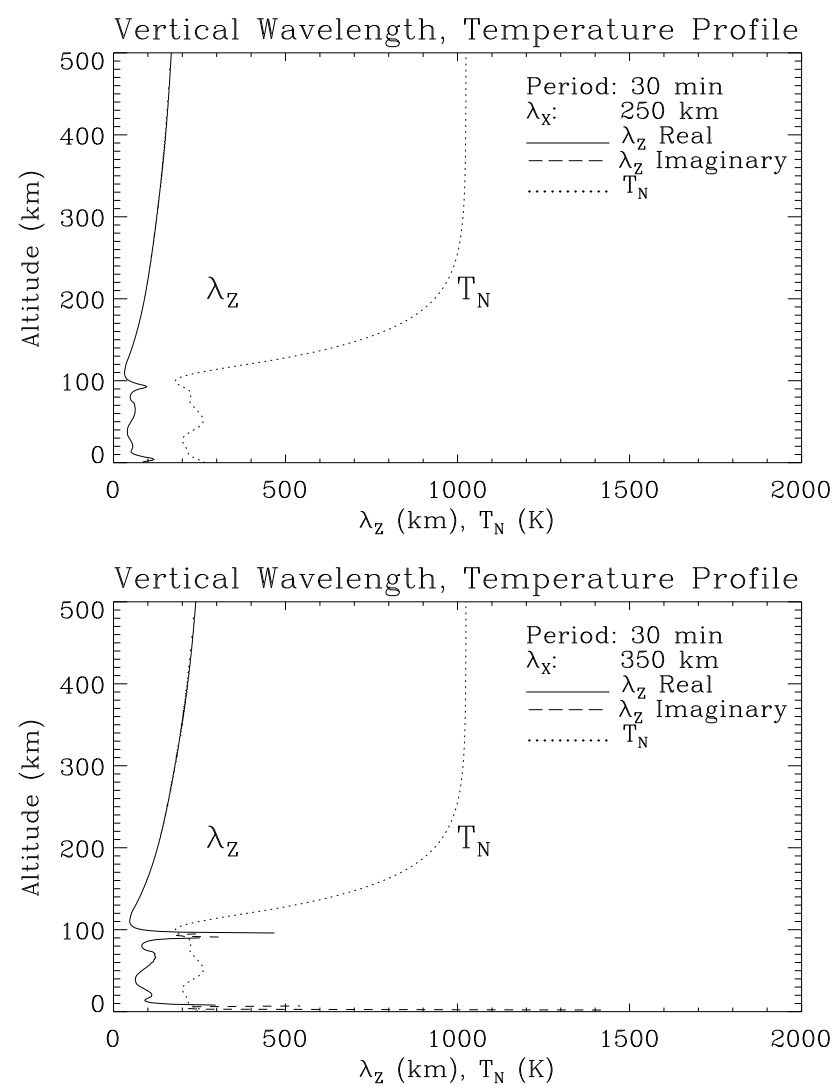

Fig. 3. Altitude profiles of the MSIS90 model atmospheric temperature and gravity wave vertical wavelength derived from dispersion Eq. (1) for a wave period of $30 \mathrm{~min}$ and horizontal wavelengths of 250 and $350 \mathrm{~km}$.

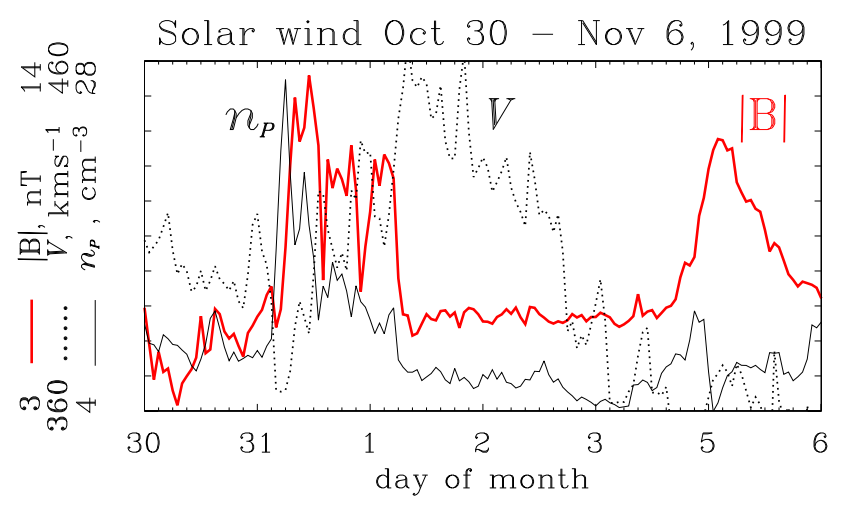

Fig. 4. The co-rotating solar wind plasma stream and interaction region observed by the ACE spacecraft. Alfvén waves were observed in the stream after the magnetic field magnitude leveled off. The day of month labels are placed at 00:00 UT of each day.

GSE coordinates. Inside the solar wind, the spacecraft observed large amplitude Alfvénic fluctuations. IMP 8 was in the most suitable location to monitor the solar wind impact upon the Earth's dayside magnetosphere. Figure 5 shows the IMP-8 IMF (solid lines) and plasma data (small crosses), demonstrating the presence of Alfvén waves in the 


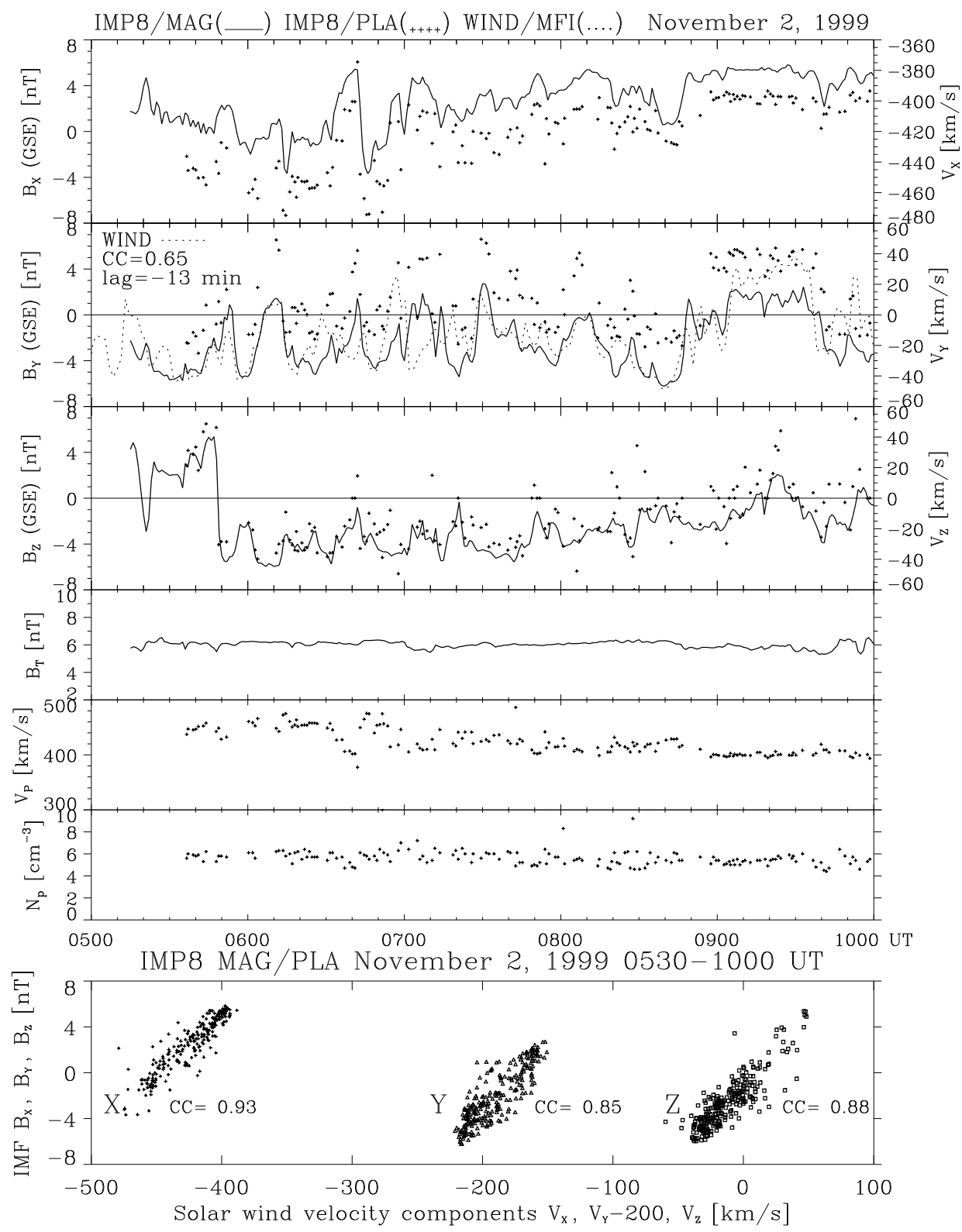

Fig. 5. The IMF (solid line) and solar wind plasma parameters (small crosses) indicate Alfvénic fluctuations observed by IMP 8 . The WIND IMF $B_{y}$ (dotted line) is shifted by $13 \mathrm{~min}$, which is the maximum cross-correlation lag between the IMP 8 and WIND time series. The bottom panel shows scatter plots and coefficients of correlation (CC) between the corresponding components of the IMF and ion velocity (for the $B_{y}$ versus $V_{y}$ scatter plot, the $V_{y}$ values are shifted by $-200 \mathrm{~km} / \mathrm{s}$ ).

solar wind: The corresponding components of the IMF and ion velocity fluctuations are highly correlated (scatter plots and correlation coefficients are shown in the bottom panel of Fig. 5) while the magnitude of the IMF $B_{T}$ and density $n_{p}$ remained relatively constant or fluctuated only with smaller amplitudes. For sunward oriented background IMF $\left(B_{x}>0\right)$ the positive correlations indicate antisunward propagating Alfvén waves (Belcher and Davis, 1971) advected in the solar wind. The predicted Alfvénic velocity fluctuations (Sibeck et al., 1997) obtained from the Whalen relation $\Delta \mathbf{V}= \pm \Delta \mathbf{B} /\left(\mu_{0} \rho\right)^{1 / 2}$ compare well with the observed fluctuations in $\mathbf{B}$, where $\mu_{0}, \rho, \mathbf{V}$ and $\mathbf{B}$ are the permeability of free space, the plasma mass density, ion velocity and magnetic field, respectively.

Various approaches have been adopted to estimate the arrival time of a solar wind disturbance at the subsolar magnetopause for a single spacecraft (e.g. Lester et al., 1993). With multiple spacecraft monitoring the solar wind it is possible to compute (Nishitani et al., 1999) the orientation of the plane wave phase fronts by using the cross-correlation lags between pairs of spacecraft. This procedure (Prikryl et al., 2002) is used for the period shown in Fig. 5, prior to an IMP8 data gap from 10:10 to 18:40 UT. The most conspicuous feature observed by all three spacecraft was a sudden southward 
turning of the IMF at about 05:48 UT for IMP8. This was a rotational discontinuity: the magnetic field magnitude $B_{t}$ stayed relatively constant as both the plasma velocity $V_{z}$ and the IMF $B_{z}$ changed rapidly, switching polarity. The cross-correlations from the three IMF- $B_{z}$ time series give inter-spacecraft lags of $52 \mathrm{~min}$ (ACE-IMP8), $71 \mathrm{~min}$ (ACEWIND), and $19 \mathrm{~min}$ (IMP8-WIND), with the corresponding maximum cross-correlation coefficients ranging between 0.61 and 0.75 . From the above cross-correlation lags, the propagation delays between the spacecraft and the subsolar magnetopause were estimated to be $55 \pm 1 \mathrm{~min}$ (ACE), 3 \pm 1 min (IMP8), and $-16 \pm 1$ min (WIND) for the solar wind speed $V_{p}$ of $430 \pm 30 \mathrm{~km} / \mathrm{s}$ which characterized 2 November. The propagation delay between the subsolar magnetopause and ionosphere can range from a few minutes near the noon sector to several minutes away from it (Saunders et al., 1992). However, after sudden changes in the IMF, a rapid global ionospheric convection reconfiguration on time scales of minutes has been observed (Ruohoniemi and Greenwald, 1998).

The IMF $B_{y}$ was predominantly dawnward but showed large amplitude quasi-periodic Alfvénic fluctuations after the IMF turned southward. In general, the IMF- $B_{y}$ fluctuations observed by the three spacecraft were correlated but there were significant differences in the waveforms (WIND IMF$B_{y}$ is superposed in Fig. 5, see dotted line). This is not surprising considering the substantial spatial separation between the spacecraft (e.g. the spacecraft GSE Y coordinate varied between -13 and $-45 R_{E}$ ). The data from IMP 8 are used here because it was the most suitably located satellite for observing the Alfvén waves that interacted with the dayside bow shock and magnetopause.

\subsection{Pulsed ionospheric flows and gravity waves observed by SuperDARN}

Between 06:00 and 18:00 UT, the CUTLASS radar in Hankasalmi, Finland, observed PIFs poleward of the groundscatter signatures of gravity waves (TIDs). For the first 6 hours of this period, Fig. 6a shows the radar LOS velocity for ionospheric scatter $\left(74^{\circ}-81^{\circ}\right.$ magnetic latitude). Radar beam 13 points approximately to the geographic north, just east of Svalbard. Figure 6b shows the received groundscatter radar power in the range interval $900-1900 \mathrm{~km}$, corresponding to magnetic latitudes $66^{\circ}-74^{\circ}$. The slanted bands of strongly focused ground-scatter power indicate large amplitude equatorward-moving TID fronts in the $\mathrm{F}$ region.

The ionospheric scatter (Fig. 6a) is observed at magnetic latitudes $>75^{\circ}$, poleward of the ground-scatter. The ground magnetic field X components measured at $\mathrm{Ny}$ Åleslund (NAL; $76.1^{\circ}$ magnetic latitude) and Longyearbyen (LYR; $75.1^{\circ}$ are superposed. Only a subset of LYR data between 07:00 and 09:30 UT needed in a discussion below is shown (a thin line is used to avoid cluttering). The LOS velocity is pulsed (PIFs), reaching $-1000 \mathrm{~m} / \mathrm{s}$ (see red pixels, indicating velocity away from the radar). Before $\sim 09: 00 \mathrm{UT}$, the regions of enhanced LOS velocities (PIFs) were also regions of large spectral widths and enhanced backscatter power (not shown), indicating that they were located at the ionospheric footprint of the magnetospheric cusp (Pinnock et al., 1991; Baker et al., 1995; McWilliams, 2001), which was shifting in latitude. The equatorward shift of the ionospheric footprint of the cusp after the IMF turned southward is known to be due to the magnetic flux erosion caused by successive flux transfer events (FTEs). After 09:00 UT, the spectral widths were only moderately enhanced as the radar beam intercepted the dusk convection cell observing the flows turning from sunward to antisunward and their intensifications. While beam 13 observed these later flow bursts further poleward of the cusp in the convection throat and in the dusk cell, their dynamic behaviour was clearly related to the cusp flow/current signatures (see the discussion of the ground magnetic fluctuations at Svalbard).

To determine the PIF times and evaluate the correlation between PIFs and TIDs, time series of the radar LOS velocity and ground-scatter power were extracted for beam 13. The pure-state filtering technique (Samson, 1983) was then used to eliminate noise while preserving or enhancing the visibility of common periodicities that are present in the data from a set of neighboring range gates. In Fig. 6a, the PIFs are identified as bands of elevated LOS velocity extending $1-3^{\circ}$ in latitude and lasting a few minutes. A dashed line is drawn (Fig. 6a) through approximate centres of the PIFs that shifted in latitude. This line was used as the central "extraction" line to extract time series of LOS velocity from "dynamic" ranges, namely range cells that followed the general trend of the PIF latitude/range with time. This time series along with two additional time series from adjacent ranges were filtered as discussed below. The dashed line acted as a zero baseline to plot one of the filtered time series.

The LOS velocities from two range gates that were closest to the dashed line were averaged to form the first time series. Two additional time series were extracted by averaging the LOS velocities from pairs of adjacent ranges poleward and equatorward of the range pair that was used to form the first (central) time series. Three ground-scatter-power (TID) time series were extracted from adjacent fixed range gates (between 1155 and $1290 \mathrm{~km}$ ). Because of a significant tilt of the TID bands (Fig. 6b) no averaging of adjacent range gates was applied; as a result, the relative sharpness of the groundscatter power peaks was retained. Missing LOS velocity data were set to zero and small gaps in the ground-scatter power time series were filled with interpolated values.

The radar LOS velocity and ground-scatter power data (two sets of three time series each) were filtered separately. The raw and pure-state-filtered time series are shown in Fig. 7. The arrows indicate the times of enhanced negative LOS velocity (PIFs). For convenience of comparison, the filtered lower-latitude ground-scatter power (bottom panel) is plotted against a time axis that is shifted with respect to the higher-latitude LOS velocity panel, in order to approximately account for the TID propagation time (see below). The IMF- $B_{y}$ values observed by WIND and IMP 8 are superposed in the bottom panel and are shifted by 52 and $65 \mathrm{~min}$, 
Hankasalmi:vel,pwr_I

2 Nov $1999^{(306)}$

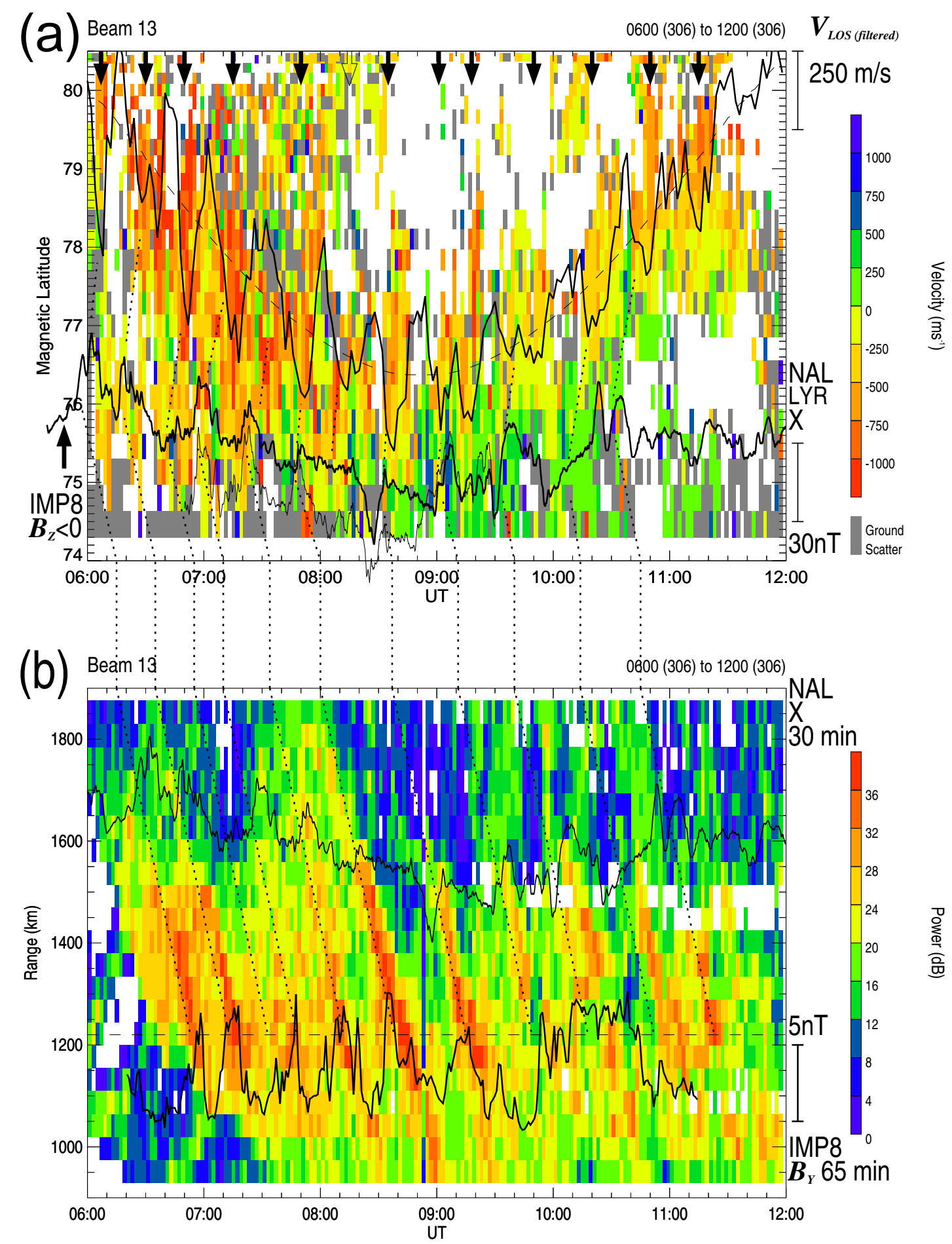

Fig. 6. (a) Radar LOS velocity at far ranges mapped in magnetic latitude and time. The downward-pointing arrows mark the PIF times determined from the pure-state filtered LOS velocity time series, one of which is plotted (top black solid line) about a zero baseline (dashed line). Also, the ground magnetic field X components measured at Ny Åleslund (NAL) and Longyearbyen (LYR; thin line) are superposed. The arrival time of the IMF $B_{z}<0$ is shown on the left. The dotted lines are drawn to suggest a correspondence between the NAL X component positive (northward) deflections and PIFs. (b) The radar ground-scatter power at near ranges. Superposed are time series of the IMP-8 IMF $B_{y}$ (shifted by $65 \mathrm{~min}$ ) and the NAL ground magnetic field X component (shifted by $30 \mathrm{~min}$ ). The dotted lines along the TID bands are superposed to show the correspondence between the ground magnetic field perturbations and the IMF- $B_{y}$ oscillations. 
respectively. The latter time lag gives the highest crosscorrelation coefficient of 0.36 when the IMP- 8 time series is correlated with the filtered TID time series at range $1200 \mathrm{~km}$. While this value is not very high, the cross-correlation function does have a well-defined peak. For the first $3 \mathrm{~h}$ of the time series shown in Fig. 7, the maximum correlation coefficient is significantly higher $(0.61)$ with the same time lag of $65 \mathrm{~min}$. The correlation coefficients for the WIND data are significantly lower. However, there is a one-to-one correspondence between the IMF- $B_{y}$ positive (duskward) turnings and TIDs. The correlation is somewhat disrupted around 10:30 UT but is restored for the following two TIDs, as indicated by the WIND data. The filtered LOS velocities show a variation that is very similar to that of the TIDs. There is a one-to-one correspondence between PIFs and TIDs, although this is not as clear as the correlation between TIDs and the IMF $B_{y}$ values. The open arrow shows a minor PIF, a localized flow burst, which occurred at $\sim 08: 15$ UT and which did not extend poleward. This minor flow burst is not associated with a TID. The ground-scatter power in the gap between the fifth and sixth TIDs is very low except for a spike at ranges near $1200 \mathrm{~km}$.

As shown by dotted lines in Fig. 6a, PIFs are associated with the northward (positive) deflections of the ground magnetic field at NAL and TIDs. The delays of up to about 10 min between the NAL X component northward deflections and the PIFs observed on beam 13 are due to the evolution of convection flow channels (FTE signatures), as discussed below. While the correspondence between PIFs and the positive deflections of the NAL trace is generally good, it is less clear around 08:00 UT. This can be explained by two possible factors, one of which is the HF propagation. The ground-scatter masked some of the ionospheric scatter and the clarity of the LOS velocity data may have been affected by anomalous HF propagation due to the focusing/defocusing of the radio waves resulting from their interaction with the TIDs. In particular, at $\sim 07: 30 \mathrm{UT}$, the fifth dotted line is drawn towards a flow burst that appears to be merging with the next one but in fact may have been masked above $77^{\circ}$ latitude by the interfering ground-scatter. Thus it is missed in the extracted PIF time series that shows only an indication of a double-humped PIF. The second factor is related to the equatorward shift of the cusp due the magnetic flux erosion by successive FTEs. This explains why the minor PIF (open arrow) that was mentioned above is not associated with a significant $\mathrm{X}$-component deflection at NAL. However, at Longyearbyen $\left(75.1^{\circ}\right)$, a clear negativeto-positive fluctuation observed at $\sim 08: 05$ UT is associated with the minor PIF. Similarly, a "double" PIF is observed between 09:00 and 09:20 UT. The LYR X component, which is otherwise well correlated with the NAL X component, contains a shorter periodicity which is reflected in the PIF rate at this time. This has been observed previously and the possibility of feedback from a field line resonance on the last closed field line to the reconnection region has been suggested (Prikryl et al., 1998).

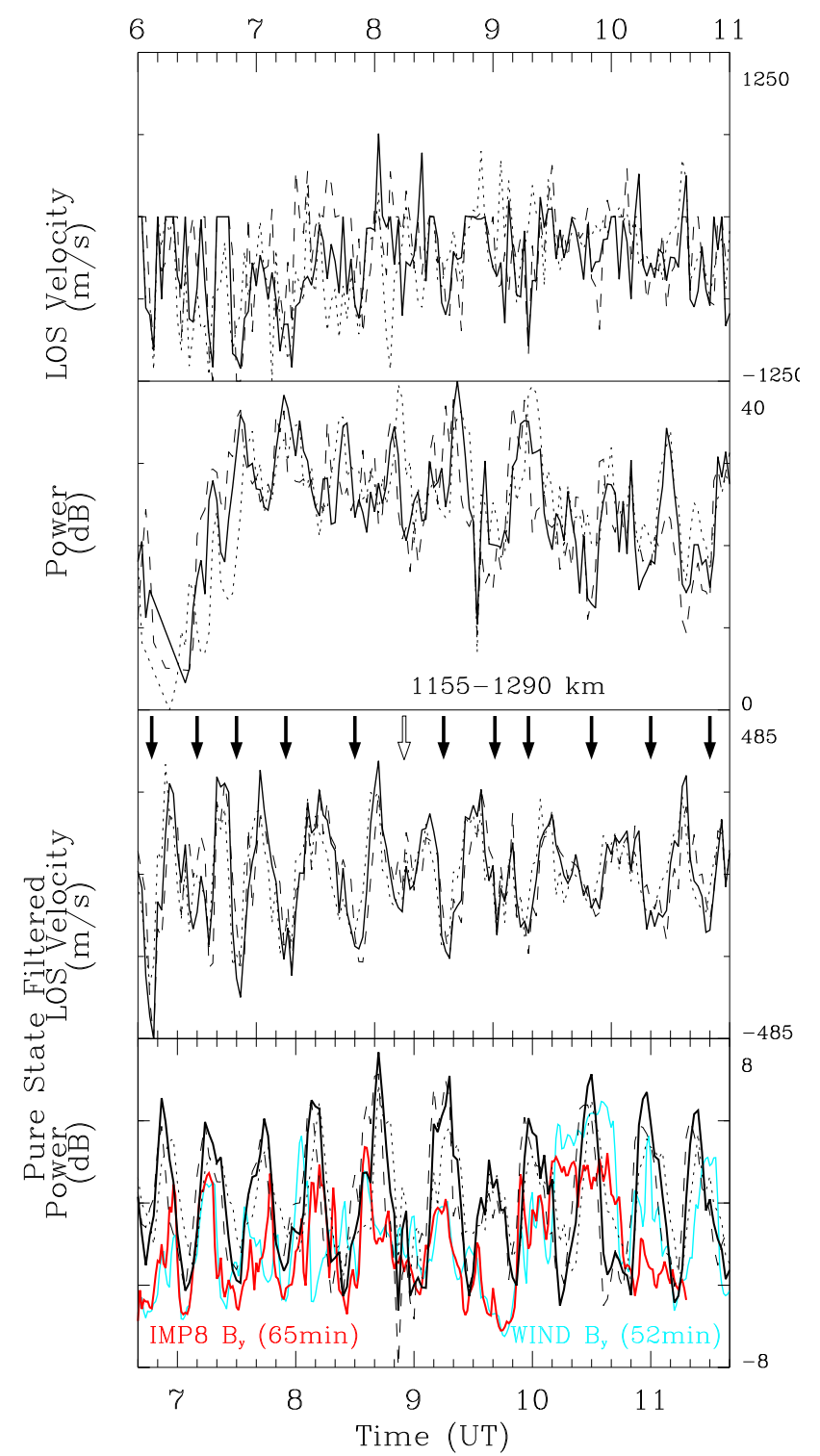

Fig. 7. Raw (top two panels) and pure-state-filtered time series extracted from the LOS velocity and ground-scatter power data for radar beam 13. Time series for adjacent ranges are shown in dotted, solid and dashed lines. The arrows indicate large negative LOS velocities (PIFs). For convenience of comparison between filtered PIFs and TIDs, the filtered ground-scatter power (bottom panel) is plotted against the time axis that is appropriately shifted with respect to those in the upper panels. The IMF- $B_{y}$ observed by IMP 8 (red line) and WIND (blue line) are shifted by 65 and $52 \mathrm{~min}$, respectively.

In Fig. 6b, the dotted lines are superposed along the TID bands to indicate the one-to-one correspondence between the northward deflections of the ground magnetic field at NAL and the IMF $B_{y}$, both being associated with TIDs. The NAL $\mathrm{X}$ time series is shifted by $30 \mathrm{~min}$ to make this association. This delay is consistent with the propagation time from a potential source of TIDs, namely the ionospheric current enhancement near the NAL magnetic latitude $\left(76^{\circ}\right)$, to the radar 

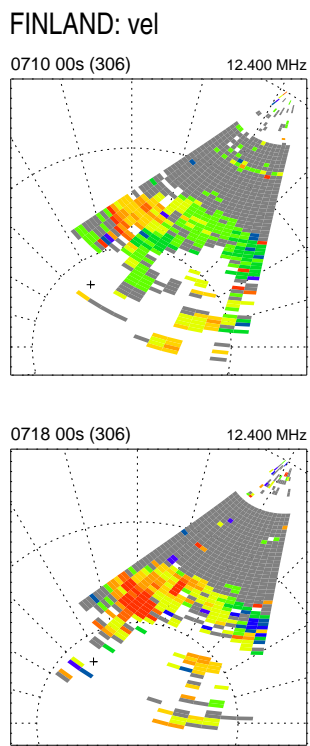

2 Nov $1999^{(306)}$
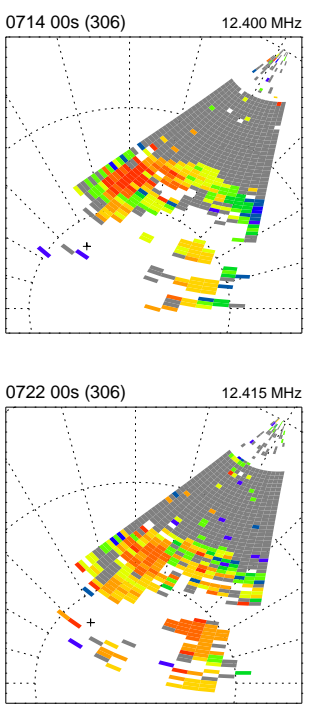

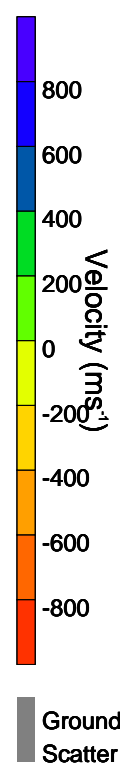

Fig. 8. The LOS velocity maps showing the evolution of a flow channel in the field-of-view of the Finland radar that was located at $\sim$ 10:00 MLT (12:00 MLT is toward the top). The $80^{\circ}, 70^{\circ}$ and a small fraction of $60^{\circ}$ magnetic latitudes are shown. The cross shows the north geographic pole. The ground-scatter is shown in gray.

range $\sim 1600 \mathrm{~km}$, as indicated by the extended dotted lines. The association of the $\mathrm{X}$-component positive deflections with PIFs has already been discussed in Fig. 6a. The positive enhancement of the NAL X component is attributed to the return eastward ionospheric current (westward flow) equatorward of the flow channel (PIF) that is a part of the ionospheric signature of an FTE, as discussed by Provan et al. (1998) for a PIF event during a period of the IMF $B_{y}>0$. The latter PIF event was also caused by solar wind Alfvén waves (Prikryl et al., 2002).

The first PIF was observed at magnetic latitude $80^{\circ}$ at $\sim 06: 05$ UT (Fig. 6a), about $15 \mathrm{~min}$ after the IMF turned southward as observed by IMP 8 (Fig. 5). This delay exceeds the estimated propagation time from IMP 8 to the ionosphere by $\sim 10 \mathrm{~min}$. However, it should be noted that the radar frequency changed at 06:00 UT from 9.9 to $12.4 \mathrm{MHz}$. This affected the HF propagation significantly; the earlier phase of the first PIF may not have been observed by the radar. In fact, a sharp northward deflection of the ground magnetic field at NAL was observed at 05:54 UT, $\sim 6 \mathrm{~min}$ after the southward IMF turning at IMP 8 . Thus, the propagation delay between the subsolar magnetopause and the dayside ionosphere was $\sim 3$ min after subtracting the estimated propagation time in the solar wind and magnetosheath $(3 \pm 1 \mathrm{~min})$. This is a typical Alfvén propagation time along the magnetic field line. The PIF delays of up to $10 \mathrm{~min}$ are consistent with the evolution of an FTE ionospheric signature. On a time scale of about $10 \mathrm{~min}$, the convection flow channel first extends in the east-west direction as it intensifies and then shifts poleward with the flow turning antisunward (Milan et al., 2000).
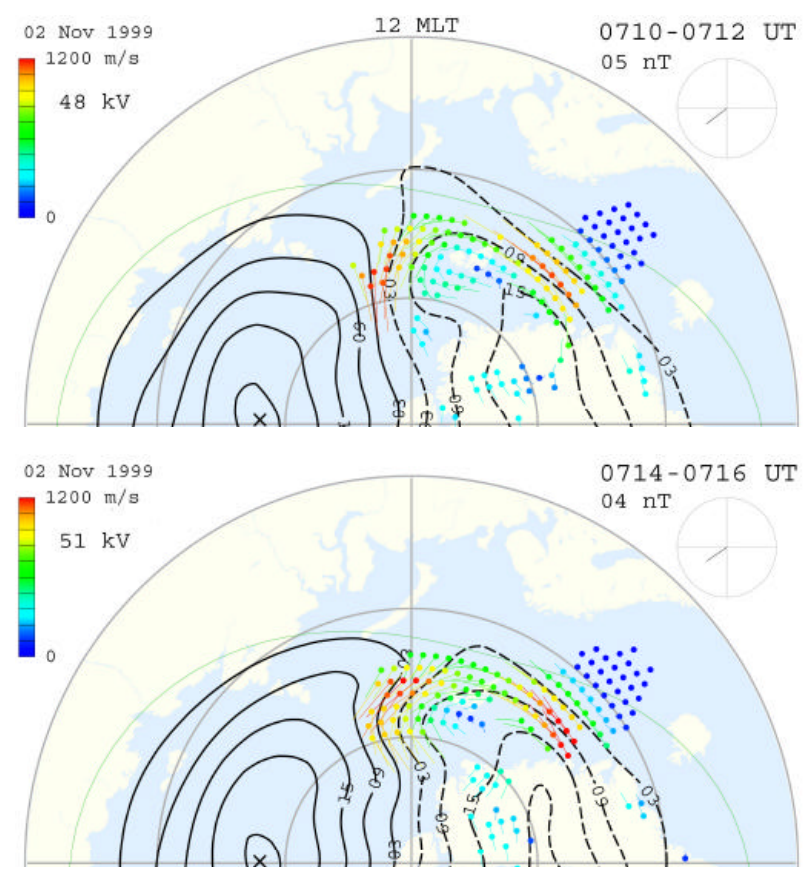

Fig. 9. The dayside portions of convection maps (centered at 12:00 MLT). The fitted convection velocity vectors are colourcoded. Contours (solid and dashed) of the electrostatic potential are shown with the value of the cross-polar cap potential difference given (top-left). The IMF $B_{z}$ vs. $B_{y}$ clock-dial plot is shown (topright).

The ground magnetic signatures observed at NAL are consistent with the current system expected for FTEs for IMF $B_{y}<0$ (Øieroset et al., 1997; their Fig. 11). In such a case, the negative-to-positive deflections of the $\mathrm{X}$ component are caused by a reversal of the ionospheric Hall currents from westward to eastward as the current system progresses poleward.

The time series analysis points to a source of TIDs in the cusp ionosphere - PIFs. However, the location and orientation of the convection flow bursts, as well as their longitudinal extent, need to be further specified. This is revealed by the LOS velocity and convection maps, the latter of which are obtained by the method of spherical harmonic fitting to all available LOS velocity data (Ruohoniemi and Baker, 1998). Figure 8 shows a sequence of LOS velocity maps from 07:10 to $07: 22$ UT. The convection maps for 07:10 and 07:14 UT are shown in Fig. 9. The flow channel was extended along the dayside portion of the dawn cell. As the flow intensified, the axis of the flow channel that was initially southward of Svalbard at 07:10 UT shifted poleward. These characteristics are consistent with the model of the ionospheric response to an FTE at the magnetopause for the IMF $B_{y}<0$ (McWilliams et al., 2000b, 2001). At $\sim 09: 00$ UT the Hankasalmi radar beam 13 intercepted the dusk cell. The PIFs occurring later were associated with the antisunward turning of the convection in the dayside portion of the dusk cell. A sequence of LOS velocity maps (Fig. 10) shows a flow channel that is similar to 
FINLAND: vel
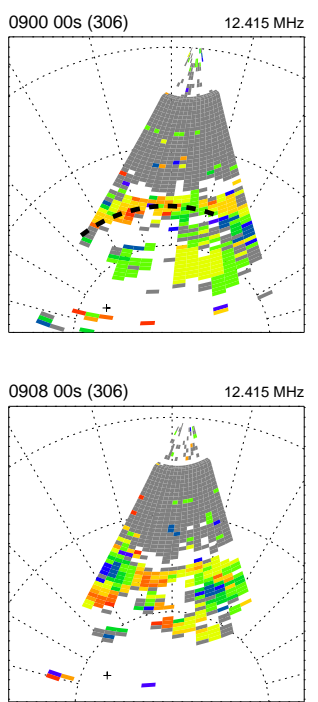

2 Nov $1999^{(306)}$
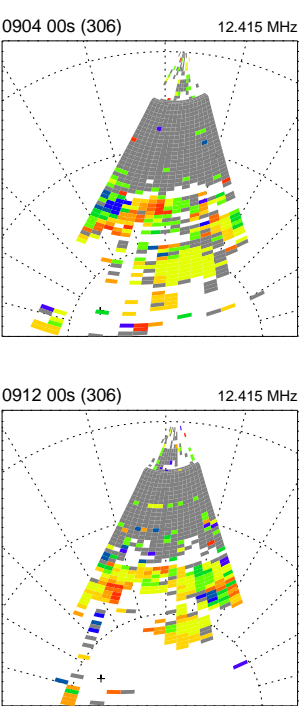

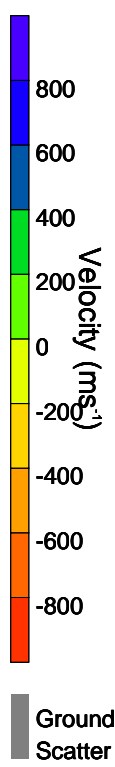

Fig. 10. The LOS velocity maps showing a flow channel in the fieldof-view of the Finland radar. The radar was located near 12:00 MLT and observed the dusk convection reversal. The approximate axis of the flow channel is superposed in the first map. The $80^{\circ}, 70^{\circ}$ and $60^{\circ}$ magnetic latitudes are shown. The cross shows the north geographic pole. The ground-scatter is shown in gray.

the one shown in Fig. 8. An approximate axis of the flow channel is superposed in the first map of the sequence. However, at this time, the easternmost beams intercepted the dusk convection cell. A sharp flow reversal boundary was observed as the dusk cell protruded over Svalbard towards the noon sector. Figure 11 shows convection maps for 09:04 and 09:08 UT. The reversal boundary extended longitudinally as the flow channel evolved by intensifying and shifting poleward. The following PIFs are associated (preceded) by enhanced positive (toward-the-radar) LOS velocities at lower latitudes (Fig. 6a).

Figure 12 shows a map of the ground-scatter power observed at 09:44 UT. The ground-scatter signature of a TID spanning the radar field-of-view along $70^{\circ}$ of magnetic latitude is interrupted in the region of low power return for central beams. The TID is associated with the convection flow burst (PIF) starting at 09:00 UT. The approximate axis of the flow channel that was observed at 09:00 UT (Fig. 10) is superposed. The radial distance of the TID band from the suggested source is between 700 and $800 \mathrm{~km}$. A trace of the previous TID signature that is associated with the PIF at 08:35 UT can be seen at near radar ranges at $\sim 66^{\circ}$ magnetic latitude. This TID crossed magnetic latitude $70^{\circ}$ at $\sim 09: 10$ UT.

The ground-scatter (Fig. 6b) shows TIDs with periods between 20 and $40 \mathrm{~min}$. Following the conclusions by MacDougall et al. (2001), we assume that, to a first approximation, the proportionality factor between the TID velocity and the rate of change of the range of the associated ground-
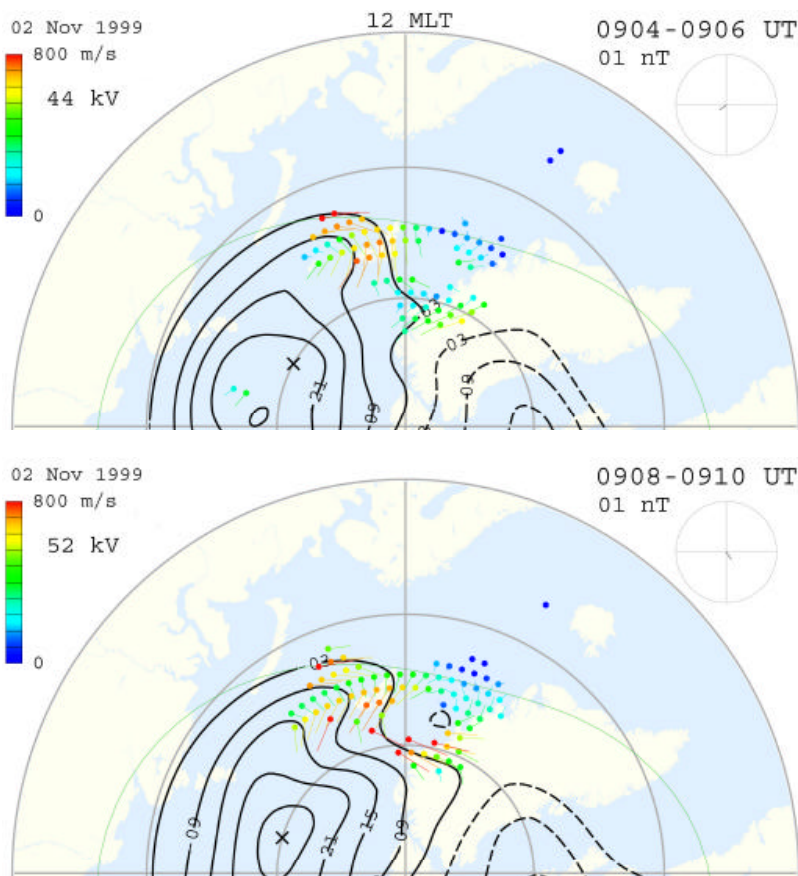

Fig. 11. The dayside portions of convection maps (centered at 12:00 MLT). The fitted convection velocity vectors are colourcoded. Contours (solid and dashed) of the electrostatic potential are shown with the value of the cross-polar cap potential difference given (top-left). The IMF $B_{z}$ vs. $B_{y}$ clock-dial plot is shown (topright).

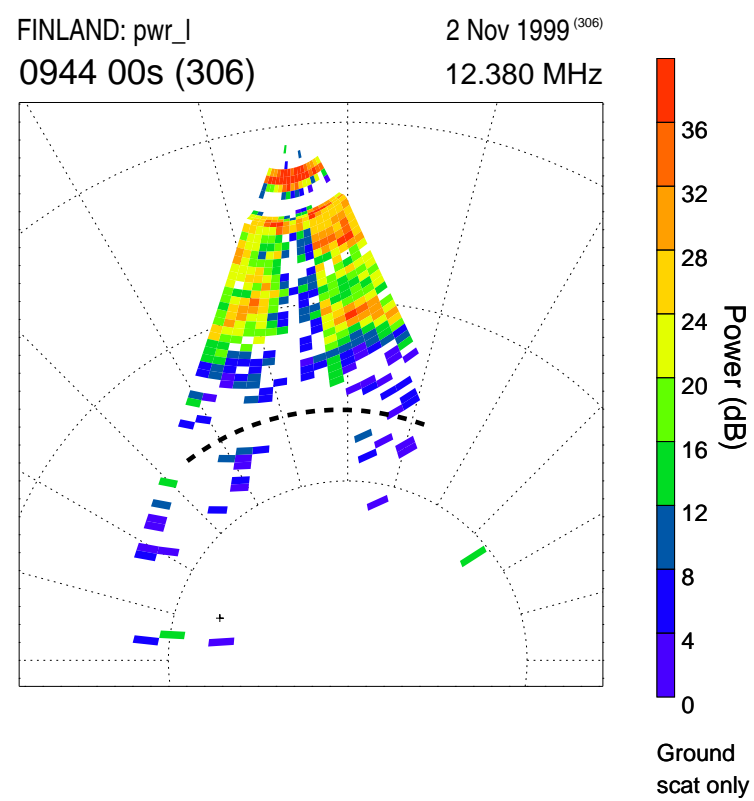

Fig. 12. The Finland radar map (12:00 MLT is toward the top) showing the ground-scatter-power signatures of TIDs. The radar was located in the afternoon sector just past 12:00 MLT. The approximate axis of the flow channel as observed at 09:00 UT is superposed. 


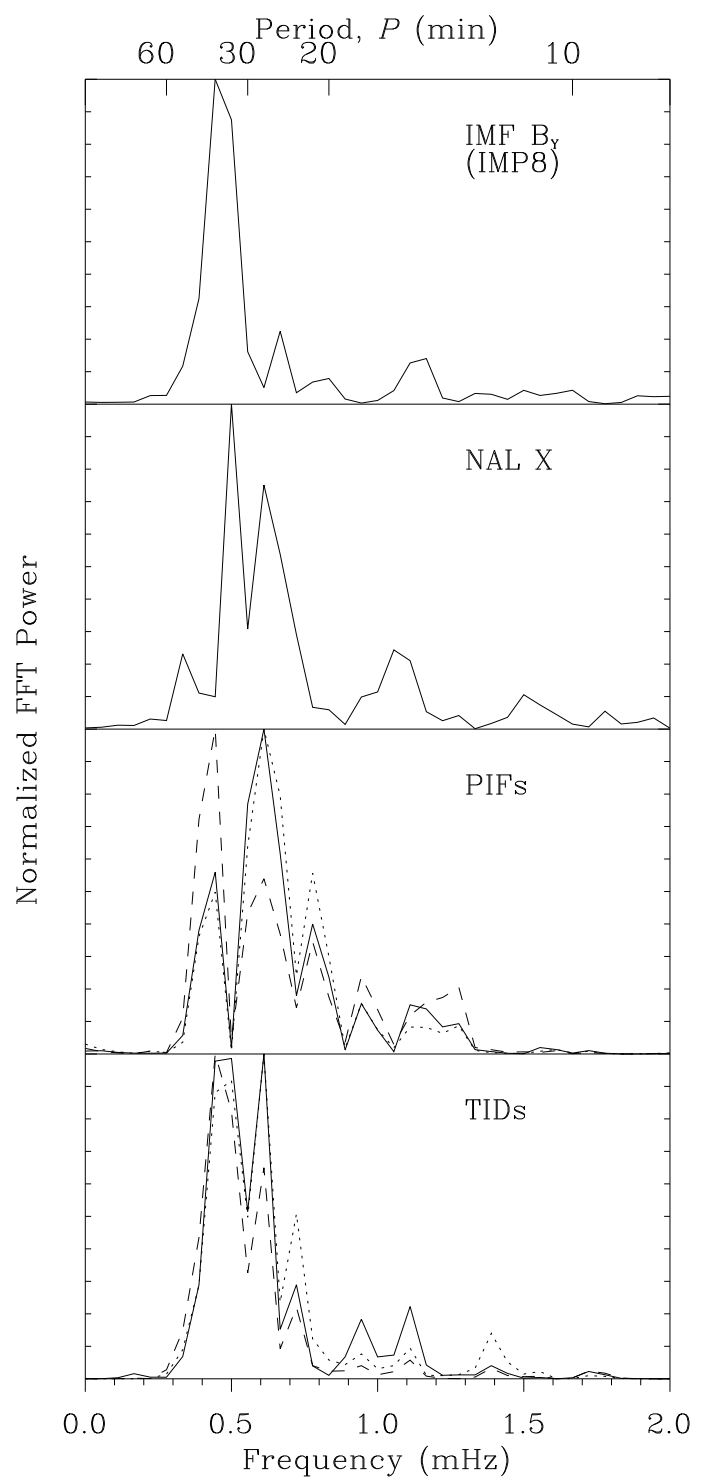

Fig. 13. Comparison of normalized spectra of the ground magnetic field X component, the IMF $B_{y}$, the pure-state-filtered radar LOS velocity (PIFs) and ground-scatter power (TIDs). The two bottom panels show the spectral power for adjacent radar ranges as dotted, solid and dashed lines.

scatter is close to 1.0. Thus, the slopes of the bands in the range-time plot (Fig. 6b) yield a mean TID horizontal velocity along beam 13 of $310 \mathrm{~m} / \mathrm{s}$, with a standard deviation of $35 \mathrm{~m} / \mathrm{s}$. For beam 4 (not shown), which was nearly perpendicular to the TID fronts, the slopes of the bands indicate an average TID phase velocity of $290 \mathrm{~m} / \mathrm{s}$, with a standard deviation of $50 \mathrm{~m} / \mathrm{s}$. The range separation between adjacent TIDs is estimated to be between 400 and $550 \mathrm{~km}$. The TID separation may be interpreted as the TID wavelength if the TIDs are caused by a gravity wave train excited by wave-like PIFs. Thus, the terms TID "wavelength" and "period" are subject to this assumption. The inferred approximate values of TID velocity and "wavelength" are consistent with the ray-tracing results shown in Fig. 2. For the group paths that reflected in the upper mesosphere upward into the $\mathrm{F}$ region, the gravity wave phase velocities exceed $250 \mathrm{~m} / \mathrm{s}$ and the horizontal wavelengths are greater than $400 \mathrm{~km}$.

The time lag of 65 min that was determined by crosscorrelating the IMF- $B_{y}$ and TID time series is a good representation of the expected propagation delay, which is a sum of propagation delays in solar wind, magnetosheath, magnetosphere and ionosphere. Almost $60 \mathrm{~min}$ of this delay is due to the TID/AGW propagation time from a source in the cusp footprint. This value is consistent with the phase velocities inferred from the observed TID front progressions, as well as the ray-tracing results for group paths reaching $\mathrm{F}$ region via reflection from temperature gradients near $100 \mathrm{~km}$ altitude. The observed time delay is too short to accommodate ground-reflected AGWs as the cause of the observed TIDs.

Also, the distance between the suggested TID source in the cusp ionosphere and the ground-scatter TID signatures is inconsistent with the Earth-reflected type of AGWs. The clearest ground-scatter signatures were observed between the radar ranges 900 and $1600 \mathrm{~km}$ (Fig. 6b), which correspond to maximum and minimum distance from NAL latitude of $\sim 1200$ and $500 \mathrm{~km}$, respectively. This is too short a distance for Earth-reflected AGWs to reach the F region. Even if a range factor of 0.5 was assumed for TID signatures (which would be inconsistent with the above propagation delay estimations), the observed TID distances from the suggested source region $\left(\sim 76^{\circ}\right)$ would be between $\sim 1700$ and $1300 \mathrm{~km}$. This is still too short a distance to accommodate both the downward and upward legs of the group path for Earth-reflected AWGs (Fig. 2). Furthermore, the Earth-reflected AGWs would require much longer propagation times due to significantly reduced phase and group velocities. Also, the Earth-reflected AGWs would be dispersed and show wave packets (Francis, 1974), so that a one-to-one correspondence between the TIDs and their sources would not be possible to find. Thus, we conclude that these TIDs were not due to Earth-reflected AGWs.

Finally, a time series analysis of wave phenomena would not be complete without an estimate of the spectral components. The fast Fourier transform (FFT) spectra of the IMF, ground magnetic field, PIFs and TIDs are similar. The two top panels of Fig. 13 show the normalized spectra of the IMF $B_{y}$ component and the ground magnetic field $\mathrm{X}$ component, for comparison with the normalized pure-state spectra of the radar LOS velocity (PIFs) and ground-scatter power (TIDs) shown in the two lower panels. The magnetic field time series were detrended (high-pass filtered) to remove very low frequency components. A Hanning window was applied to the time series before computing the FFT spectra. All spectra show that most of the spectral power resides at frequencies between $\sim 0.4$ and $0.8 \mathrm{MHz}$ (periods between 42 and $21 \mathrm{~min}$ ). The gravity wave period of $30 \mathrm{~min}$ was used for ray tracing.

In summary, the solar wind Alfvénic fluctuations of the IMF $B_{y}$ are correlated with TIDs observed by SuperDARN. A one-to-one correspondence between the IMF $B_{y}$ values 
and the TIDs suggests a cause-effect relationship through solar wind coupling to the dayside magnetosphere. The TIDs are traced to a source in the dayside ionosphere - PIFs and/or the associated ionospheric current intensifications. The computed cross-correlation lag between the IMF $B_{y}$ and TID time series is the sum of the propagation delays in the solar wind, magnetosheath, magnetosphere and ionosphere. The dominant delay, which is due to AGW propagation from the suggested ionospheric source, is consistent with the AGW ray-tracing results (Sect. 3).

\section{Solar wind forcing in the upper atmosphere}

A one-to-one correspondence among solar wind Alfvén waves, PIFs/ionospheric current intensifications and TIDs points to a cause-effect relationship. It indicates that the observed wave fronts of AGWs/TIDs were produced by a series of quasi-periodic pulses in the convection electric field (PIFs) and/or associated ionospheric current rather than a continuous wave train generated by a single pulse. This is similar to model predictions (Millward et al., 1993a,b; Millward, 1994). Millward et al. (1993b) stated that, "there is a (rough) one-to-one correspondence between electric field bursts and associated AGWs/TIDs". Periodic bursts in the electric field produced gravity waves (sequence of gravity wave pulses) with the same period as the electric field (Millward et al., 1994). These authors showed that, as a result of a resonance effect, the modeled amplitude of the gravity waves was dependent on the repetition period and peaked at periods of about $40-50 \mathrm{~min}$.

Cases of PIFs resulting from solar wind MHD waves that modulate the convection electric field have been shown previously (Prikryl et al., 1998, 2002). It is logical to extend coupling to the neutral atmosphere via Joule heating or Lorentz forcing which produce AGWs/TIDs. Huang et al. (1998a) concluded that the gravity waves they observed with SuperDARN could be traced back to ionospheric perturbations observed poleward of the ground-scatter signatures of TIDs. When two-dimensional (time and range) crosscorrelation analysis between the ground and ionospheric backscatter power was performed, it showed that the maximum correlation occurred for a range separation of about $1100 \mathrm{~km}$ (Huang et al., 1998a). In agreement with the latter result, for the case study presented here, the range separations between the suggested TID source regions and the subsequent TID ground-scatter signatures are estimated to be between $\sim 500$ and $1200 \mathrm{~km}$. In addition, the derived TID wavelengths and phase velocities/propagation times indicate that the AGWs were reflected in the upper mesosphere, and therefore they were not Earth-reflected AGWs.

The PIFs observed by SuperDARN in the cusp footprint are interpreted as ionospheric signatures of pulsed reconnection in the form of successive flux transfer events (FTEs) (Provan et al., 1998; Provan and Yeoman, 1999; Milan et al., 2000; McWilliams et al., 2000a,b; Neudegg et al., 2000). The flow channel associated with an FTE is known to result from the passage of newly-merged magnetic flux tubes that are subject to a curvature force (magnetic tension) and solar wind drag (Lockwood et al., 1990; Cowley et al., 1991). The newly-reconnected flux tube accelerates azimuthally while moving antisunward. For IMF $B_{y}<0$ conditions, the duskward and poleward motion of the reconnected flux tube in the pre-noon magnetosphere arises due to dawnward and southward directed IMF, and results in the observed ionospheric convection signature. Such east-west extended flow channels are the likely sources of the AGWs/TIDs.

Milan et al. (2000) and McWilliams et al. (2001) examined the relative locations of the UV aurora and HF radar signatures of the magnetopause reconnection. The UV aurora was produced by precipitation due to particle acceleration in response to reconnection. McWilliams et al. (2001) pointed out that in both cases (duskward and dawnward oriented IMF) "the reconnection $\mathrm{X}$ line that originated near local noon appeared to propagate azimuthally along the postnoon magnetopause". As shown by Milan et al. (2000), the reconnection signature observed in the UV images takes the form of bands of UV aurora that appear to bifurcate and move azimuthally eastward. These bands can extend several hours in local time. More recently, Rae et al. (2004) associated PIFs with solar wind Alfvén wave modulated cusp particle signatures. Thus, the cusp precipitation and the associated field-aligned currents may also play a role in the generation of AGWs.

It should be noted that Alfvén wave coupling to the magnetosphere is only one possible source of PIFs that may generate TIDs. In principle, solar wind compressional fluctuations or internal magnetospheric processes that lead to magnetospheric pulsations can also generate TIDs as long as the periods are greater than the Brunt-Väisälä period. Also, a single burst of energetic particle precipitation, ionospheric electric field or current may launch a gravity wave. However, considering the abundance of Alfvén waves in the solar wind (at least $\sim 50 \%$ of time; Belcher and Davies, 1971), they represent an important source of the IMF fluctuations that can generate PIFs/TIDs. In addition to cusp/cleft sources of TIDs, Bristow et al. (1994) identified a source region in the afternoon high-latitude sector. In such a case, the convection flow enhancements generated by pressure pulses in the magnetosheath through the interaction of solar wind Alfvén waves with the bow shock (Lin et al., 1996) may be a source of PIFs/TIDs. This was probably the case during the next $6 \mathrm{~h}$ after 12:00 UT, following the time interval covered by the case study presented here, when the convection in the dusk cell continued to be pulsed by solar wind Alfvén waves. Corresponding TIDs were observed by the Finland radar.

\section{Conclusions}

Solar wind Alfvén waves coupling to the dayside magnetosphere are observed to pulse the ionospheric convection and associated current in the cusp footprint and dusk convection cell. These results are consistent with previous work (referenced in this paper) which suggested that the 
solar wind MHD waves can directly drive magnetospheric pulsations. Associated with the ionospheric signatures of pulsed magnetic reconnection are radar ground-scatter signatures of travelling ionospheric disturbances (TIDs) at ranges well equatorward of the pulsed ionospheric flows (PIFs). A case study is presented of TIDs that are correlated with the Alfvénic IMF- $B_{y}$ oscillations. It is suggested that PIFs or the associated ionospheric currents and/or particle precipitation - all parts of the ionospheric signature of an FTE - are possible sources of atmospheric gravity waves, which then cause TIDs. The observed one-to-one correspondences between the convection electric field bursts and/or ionospheric current fluctuations and the TIDs are consistent with the modeling results for large-scale TIDs by Millward et al. (1993a, 1993b). The correlation with solar wind Alfvén waves points to very direct coupling of energy in the solar wind into the subauroral atmosphere. The range separation of less than $1200 \mathrm{~km}$ between the suggested TID source and the groundscatter signatures of the TIDs indicates that the observed TIDs were not due to Earth-reflected gravity waves. The TID propagation times, horizontal wavelengths and phase velocities deduced from the ground-scatter are consistent with the results of ray tracing of the gravity wave energy from an ionospheric source. The rays first travel downward to the upper mesosphere, where the temperature gradients cause the rays to reflect/refract upwards. They then propagate up to the $\mathrm{F}$ region, where the gravity waves cause the undulations in the electron density observed by the SuperDARN radars as intensity fluctuations of the ground-scatter signals.

\section{Appendix A Validity of ray tracing}

Equation (9.61) of Budden (1961) gives the condition under which ray tracing is a good approximation for electromagnetic waves with horizontal polarization at oblique incidence in the ionosphere. If the condition fails, the full wave theory should be used for an accurate description of the field. A similar condition would apply to AGWs since the amplitude is governed by the same differential equation. This can be determined by double differentiation of Eq. (13) of Hines (1960) for the vertical component of the velocity perturbation, which results in the equation

$$
\frac{d^{2} A}{d z^{2}}+k_{z}^{2} A=0
$$

where $A$ is the $y$ component of the electric field of the wave in the electromagnetic case and $A$ is proportional to the $z$ component of the velocity perturbation of the atmosphere in the AGW case, $z$ is the height and $k_{z}$ is the vertical component of the wave number in the atmosphere. If (9.61) of Budden (1961) is modified for the present case $\left(k_{z}\right.$ used here is equivalent to Budden's $k q$ ), the result is

$$
F \equiv\left|0.75\left(\frac{d k_{z}}{k_{z}^{2} d z}\right)^{2}-0.5\left(\frac{d^{2} k_{z}}{k_{z}^{3} d z^{2}}\right)\right| \ll 1
$$

Applying this condition to some of the curves in Figure 2, the following results are obtained: For $\alpha_{0}=1^{\circ}, F<1$ for $z>119 \mathrm{~km}$ and $F<0.1$ for $z>136 \mathrm{~km}$. For $\alpha_{0}=80^{\circ}, F<1$ for $z>108 \mathrm{~km}$ and $F<0.1$ for $z>115 \mathrm{~km}$. For $\alpha_{0}=82^{\circ}, F<1$ for $z>99 \mathrm{~km}$ and $F<0.1$ for $z>101 \mathrm{~km}$. For $\alpha_{0}=1^{\circ}, \alpha_{0}=80^{\circ}$ and $\alpha_{0}=82^{\circ}$, the rays initially go downward and have raytheory reflection heights at 110,104 and $98 \mathrm{~km}$, respectively. Hence, there is a region for which ray theory is not valid. However, Budden states that, in the region of validity, only a trivial modification is required to the ray-tracing results provided all of the wave energy is reflected at lower heights in the atmosphere. In this case, wave theory indicates that the ray theory is valid except for a phase shift of $-\pi / 2$ for the reflected ray.

For $\alpha_{0}=83^{\circ}$, the ray only propagates downward in the at mosphere until it is reflected at the ground; $F<0.1$ at all heights before and after reflection. Thus, the ray path is probably accurate at all heights.

In order to solve (A1) numerically, using full-wave theory to find $A(z)$, it is necessary to know $d A / d z$ accurately at some height in the atmosphere. Unfortunately, this is not possible unless all of the wave energy is reflected. Below the ray-theory reflection height, $k_{z}^{2}<0$ in a layer varying from a few kilometres to tens of kilometres in thickness. Since the vertical wavelength is larger than this, wave energy can tunnel through this layer. For present purposes, the fraction of wave energy $R$ that tunnels through the layer can be approximated by

$R=\exp \left(-2 \int_{z_{0}}^{z_{r}} k_{z i} d z\right)$,

where $z_{r}$ is the reflection height where $k_{z}=0$, and $z_{0}$ is the bottom of the layer where $k_{z}=0$ and $k_{z i}=\left(-k_{z}^{2}\right)^{1 / 2}$.

For $\alpha_{0}=81^{\circ}, R=0.02$, i.e. $2 \%$ of the wave energy tunnels through the layer for which $k_{z}^{2}<0$ (evanescent layer) which extends from $z=102 \mathrm{~km}$ to $z=51 \mathrm{~km}$. From $z=51 \mathrm{~km}$ to $z=33 \mathrm{~km}, k_{z}^{2}>0$. Below $33 \mathrm{~km}, k_{z}^{2}<0$ and virtually all of the tunnelled energy is reflected above the ground level. For $\alpha_{0}=82^{\circ}, 44 \%$ of the wave energy tunnels through the evanescent layer which extends from $z=98$ to $88 \mathrm{~km}$. There is also an evanescent layer below $z=10 \mathrm{~km}$ and about $23 \%$ of the original wave energy reaches the ground where it is reflected.

Acknowledgements. The operations of SuperDARN in the Northern Hemisphere are supported by the funding agencies of the U.S., Canada, the U.K., France, and Japan. The CUTLASS radar is supported by the Particle Physics and Astronomy Research Council (PPARC), UK, the Swedish Institute for Space Physics, Uppsala, and the Finnish Meteorological Institute, Helsinki. The IMAGE magnetometer data used in this paper were collected as a GermanFinnish-Norwegian-Polish project conducted by the Technical University of Braunschweig. The computer code for the pure-statefilter time series analysis was provided by J. C. Samson, University of Alberta. We acknowledge contributions of the ACE, IMP 8, SOHO, Wind and SuperDARN teams. The solar wind data were provided by CDAWeb, a joint effort among SPDF, NSSDC and ISTP.

Topical Editor M. Lester thanks M. Pinnock and another referee for their help in evaluating this paper. 


\section{References}

Alfvén, H.: Existence of electromagnetic-hydrodynamic waves, Nature, 150, 405-406, 1942.

Baker, K. B., Dudeney, J. R., Greenwald, R. A., Pinnock, M., Newell, P. T., Rodger, A. S., Mattin, N., and Meng, C.-I.: HF radar signatures of the cusp and low-latitude boundary layer, J. Geophys. Res., 100, 7671-7695, 1995.

Bertin, F., Testud, J., and Kersley, L.: Medium-scale gravity waves in the ionospheric F-region and their possible origin in weather disturbances, Planet. Space Sci., 23, 493-507, 1975.

Belcher, J. W. and Davis, L., Jr.: Large-amplitude Alfvén waves in the interplanetary medium, 2, J. Geophys. Res., 76, 3534-3563, 1971.

Bristow, W. A., Greenwald, R. A., and Samson, J. C.: Identification of high-latitude acoustic gravity wave sources using the Goose Bay HF radar, J. Geophys. Res., 99, 319-331, 1994.

Bristow, W. A., Greenwald, R. A., and Villain, J. P.: On the seasonal dependence of medium-scale atmospheric gravity waves in the upper atmosphere at high latitudes, J. Geophys. Res., 101, 15 685-15 699, 1996.

Burlaga, L. F., Harvey, K. L., and Sheeley, N. R., Jr.: A transitory corotating stream, a short-lived coronal hole, and related magnetic fields, J. Geophys. Res., 106, 24 915-24 922, 2001.

Budden, K. G.: Radio Waves in the Ionosphere, Cambridge University Press, New York, 1961

Chimonas, G. and Hines, C. O.: Atmospheric gravity waves launched by auroral currents, Planet. Space Sci., 18, 565-582, 1970.

Chimonas, G.: The equatorial electrojet as a source of long period travelling ionospheric disturbances, Planet. Space Sci., 18, 583589,1970

Cowley, S. W. H., Freeman, M. P., Lockwood, M., and Smith, M. F.: The ionospheric signature of flux transfer events, in Proceedings of the International Workshop on Cluster: Dayside Polar Cusp, ESA SP-330, 1005-1112, 1991.

Crowley, G. and Williams, P. J. S.: Observations of the source and propagation of atmospheric gravity waves, Nature, 328, 231233, 1987.

Francis, S. H.: Acoustic-gravity modes and large-scale traveling ionospheric disturbances of a realistic, dissipative atmosphere, J. Geophys. Res., 78, 2278-2301, 1973.

Francis, S. H.: A theory of medium-scale traveling ionospheric disturbances, J. Geophys. Res., 79, 5245-5260, 1974.

Greenwald, R. A., Baker, K. B., Dudeney, J. R., Pinnock, M., Jones, T. B., Thomas, E. C., Villain, J.-C., Cerrisier, J.-C., Senior, C., Hanuise, C., Hunsucker, R. D., Sofko, G., Koehler, J., Nielsen, E., Pellinen, R., Walker, A. D. M., Sato, N. and Yamagishi, H.: DARN/SUPERDARN A global view of the dynamics of highlatitude convection, Space Sci. Rev., 71, 761-796, 1995.

Hall, G. E., MacDougall, J. W., Cecile, J.-F., Moorcroft, D. R., and St.-Maurice, J.-P.: Finding gravity wave source positions using the Super Dual Auroral Radar Network, J. Geophys. Res., 104, 67-78, 1999.

Hassam, A. B.: Transmission of Alfvén waves through the earth's bow shock: Theory and observation, J. Geophys. Res., 83, 643$653,1978$.

Hedin, A. E.: Extension of the MSIS thermosphere model into the middle and lower atmosphere, J. Geophys. Res., 96, 1159-1172, 1991.

Hines, C. O.: Internal atmospheric gravity waves at ionospheric heights, Can. J. Phys., 38, 1441-1481, 1960.
Hocke, K. and Schlegel, K.: A review of atmospheric gravity waves and traveling ionospheric disturbances: 1982-1995, Ann. Geophys., 14, 917-940, 1996,

SRef-ID: 1432-0576/ag/1996-14-917.

Hollweg, J. V., Bird, M. K., Volland, H., Edenhofer, P., Stelzried, C. T., and Seidel, B. L.: Possible evidence for coronal Alfvén waves, J. Geophys. Res., 87, 1-8, 1982.

Huang, C. S., André, D. A., and Sofko, G. J.: High-latitude ionospheric perturbations and gravity waves: 1 . Observational results, J. Geophys. Res., 103, 2131-2141, 1998a.

Huang, C. S., André, D. A., and Sofko, G. J.: Observations of solar wind directly driven auroral electrojets and gravity waves, J. Geophys. Res., 103, 23 347-23 356, 1998 b.

Hunsucker, R.: Atmospheric gravity waves generated in the highlatitude ionosphere: a review, Rev. Geophys. Space Phys., 20, 293-315, 1982.

Hunsucker, R. D. and Tveten, L. H.: Large traveling-ionosphericdisturbances observed at midlatitudes utilizing the high resolution h.f. backscatter technique, J. Atmos. Terr. Phys., 29, 909916, 1967.

Kepko, L., Spence, H. E., and Singer, H. J.: ULF waves in the solar wind as direct drivers of magnetospheric pulsations, Geophys. Res. Lett., 29 (8), 10.1029/2001GL014105, 2002.

King, J. H.: Availability of IMP-7 and IMP-8 data for the IMS period, in The IMS Source Book, edited by Russell, C. T. and Southwood, D. J., American Geophysical Union, 10-20, 1982.

Lester, M., de la Beaujardière, O., Foster, J. C., Freeman, M. P., Lühr, H., Ruohoniemi, J. M., and Swider, W.: The response of the large scale ionospheric convection pattern to changes in the IMF and substorms: results from the SUNDIAL 1987 campaign, Ann. Geophys., 11, 556-571, 1993.

Lewis, R. V., Williams, P. J. S., Millward, G. H., and Quegan, S.: The generation and propagation of atmospheric gravity waves from activity in the auroral electrojet, J. Atmos. Terr. Phys., 58, 807-820, 1996.

Lin, Y., Lee, L. C., and Yan, M.: Generation of dynamic pressure pulses downstream of the bow shock by variations in the interplanetary magnetic field orientation, J. Geophys. Res., 101, 479493, 1996.

Lockwood, M., Cowley, S. W. H., Sandholt, P. E., and Lepping, R. P.: The ionospheric signatures of flux transfer events and solar wind dynamic pressure changes, J. Geophys. Res., 95, 17113 17 135, 1990.

McComas, D. J., Bame, S. J., Barker, P., Feldman, W. C., Phillips, J. L., Riley, P., and Griffee, J. W.: Solar Wind Electron Proton Alpha Monitor (SWEPAM) for the Advanced Composition Explorer, Space Sci. Rev., 86, 561-612, 1998.

MacDougall, J. W., Hall, G. E., and Hayashi, K.: F region gravity waves in the central polar cap, J. Geophys. Res., 102, 14513 $14530,1997$.

MacDougall, J. W., Andre, D. A., Sofko, G. J., Huang, C.-S., and Koustov, A. V.: Travelling ionospheric disturbance properties deduced from Super Dual Auroral Radar measurements, Ann. Geophys., 18, 1550-1559, 2001,

SRef-ID: 1432-0576/ag/2000-18-1550.

McKenzie, J. F. and Westphal, K. O.: Transmission of Alfvén waves through the earth's bow shock, Planet. Space Sci., 17, 10291037, 1969.

McWilliams, K. A., Yeoman, T. K., and Provan, G.: A statistical survey of dayside pulsed ionospheric flows as seen by the CUTLASS Finland HF radar, Ann. Geophys., 18, 445-453, 2000a, SRef-ID: 1432-0576/ag/2000-18-445. 
McWilliams, K. A., Yeoman, T. K., and Cowley, S. W. H.: Twodimensional electric field measurements in the ionospheric footprint of a flux transfer event, Ann. Geophys., 18, 1584-1598, 2000b,

\section{SRef-ID: 1432-0576/ag/2000-18-1584}

McWilliams, K. A., Milan, S. E., Yeoman, T. K., Sigwarth, J. B., and Frank, L. A.: Interplanetary magnetic field $B_{y}$ dependence of the relative position of the dayside ultraviolet auroral oval and the HF radar cusp, J. Geophys. Res., 106, 29 027-29 036, 2001.

Milan, S. E., Lester, M., Cowley, S. W. H., and Brittnacher, M.: Convection and auroral response to a southward turning of the IMF: Polar UVI, CUTLASS, and IMAGE signatures of transient magnetic flux transfer at the magnetopause, J. Geophys. Res., 105, 15 741-15 755, 2000.

Millward, G. H., Quegan, S., Moffett, R. J., Fuller-Rowell, T. J., and Rees, D.: A modeling study of the coupled ionospheric and thermospheric response to an enhanced high-latitude electric field event, Planet. Space Sci., 41, 45-56, 1993a.

Millward, G. H., Moffett, R. J., Quegan, S., and Fuller-Rowell, T. J.: Effect of an atmospheric gravity wave on the midlatitude ionospheric F layer, J. Geophys. Res., 98, 19 173-19 179, 1993b.

Millward, G. H.: A resonance effect in AGWs created by periodic recurrent bursts in the auroral electric field, Ann. Geophys., 12, 94-96, 1994.

Muldrew, D. B.: An ionospheric ray-tracing technique and its application to a problem in long-distance radio propagation, IRE Trans., Vol. AP-7, No. 4, 393-396, 1959.

Neudegg, D. A., Cowley, S. W. H., Milan, S. E., Yeoman, T. K., Lester, M., Provan, G., Haerendel, G., Baumjohann, W., Nikutowski, B., Büchner, J., Auster, U., Fornacon, K.-H., Georgescu, E.: A survey of magnetopause FTEs and associated flow bursts in the polar ionosphere, Ann. Geophys., 18, 416-435, 2000, SRef-ID: 1432-0576/ag/2000-18-416.

Nishitani, N., Ogawa, T., Pinnock, M., Freeman, M. P., Dudeney, J. R., Villain, J.-P., Baker, K. B., Sato, N., Yamagishi, H., and Matsumoto, H.: A very large scale flow burst observed by the SuperDARN radars, J. Geophys. Res., 104, 22 469-22 486, 1999.

Oliver, W. L., Otsuka, Y., Sato, M., Takami, T., and Fukao, S.: A climatology of $\mathrm{F}$ region gravity waves propagation over the middle and upper atmosphere radar, J. Geophys. Res., 102, 14449 $14512,1997$.

Ogilvie, K. W. and Parks, G. K.: First results from WIND spacecraft, Geophys. Res. Lett., 23, 1179-1181, 1996.

Oyama, S., Ishii, M., Murayama, Y., Shinagawa, H., Buchert, S. C., Fujii, R., and Kofman, W.: Generation of atmospheric gravity waves associated with auroral activity in the polar F region, J. Geophys. Res., 106, 18 543-18 554, 2001.

Øieroset M., Sandholt, P. E., Lühr, H., Denig, W. F., and Moretto, T.: Auroral and geomagnetic events at cusp/mantle latitudes in the prenoon sector during positive IMF $\mathrm{B}_{y}$ conditions: Signatures of pulsed magnetopause reconnection, J. Geophys. Res., 102, 7191-7205, 1997.

Pinnock, M., Rodger, A. S., Dudeney, J. R., Greenwald, R. A., Baker, K. B., and Ruohoniemi, J. M.: An ionospheric signature of possible enhanced magnetic field line merging on the dayside magnetopause, J. Atmos. Terr. Phys., 53, 201-212, 1991.

Potemra, T. A., Lühr, H., Zanetti, L. J., Takahashi, K.,. Erlandson, R. E, Marklund, G. T., Block, L. P., Blomberg, L. G., and Lepping, R. P.: Multisatellite and ground-based observations of transient ULF waves, J. Geophys. Res., 94, 2543-2554, 1989.

Prikryl, P., Greenwald, R. A., Sofko, G. J., Villain, J. P., Ziesolleck, C. W. S., and Friis-Christensen, E.: Solar-wind driven pulsed magnetic reconnection at the dayside magnetopause, Pc5 compressional oscillations, and field line resonances, J. Geophys. Res., 103, 17 307-17 322, 1998.

Prikryl, P., MacDougall, J. W., Grant, I. F., Steele, D. P., Sofko, G. J., and Greenwald, R. A.: Observations of polar patches generated by solar wind Alfvén wave coupling to the dayside magnetosphere, Ann. Geophys., 17, 463-489, 1999,

SRef-ID: 1432-0576/ag/1999-17-463.

Prikryl, P., Provan, G., McWilliams, K. A., Yeoman, T. K.: Ionospheric cusp flows pulsed by solar wind Alfvén waves, Ann. Geophys., 20, 161-174, 2002,

SRef-ID: 1432-0576/ag/2002-20-161.

Provan, G., Yeoman, T. K., Milan, S. E.: CUTLASS Finland radar observations of the ionospheric signatures of flux transfer events and the resulting plasma flows, Ann. Geophys., 16, 1411-1422, 1998,

SRef-ID: 1432-0576/ag/1998-16-1411.

Provan, G. and Yeoman, T. K.: Statistical observations of the MLT, latitude and size of pulsed ionospheric flows with the CUTLASS Finland radar, Ann. Geophys., 17, 855-867, 1999,

SRef-ID: 1432-0576/ag/1999-17-855.

Rae, I. J., Fenrich, F. R., Lester, M., McWilliams, K. A., and Scudder, J. D.: Solar wind modulation of cusp particle signatures and their associated ionospheric flows, J. Geophys. Res., 109, A03223, doi: 10.1029/2003JA010188, 2004.

Richmond, A. D.: Gravity wave generation, propagation, and dissipation in the thermosphere, J. Geophys. Res., 83, 4131-4145, 1978.

Ruohoniemi, J. M. and Baker, K. B.: Large-scale imaging of highlatitude convection with Super Dual Auroral Radar Network HF radar observations, J. Geophys. Res., 103, 20 797-20 811, 1998.

Ruohoniemi, J. M. and Greenwald, R. A.: The response of highlatitude convection to a sudden southward IMF turning, Geophys. Res. Lett., 25, 2913-2916, 1998.

Samson, J. C.: Pure states,polarized waves, and principal components in the spectra of multiple geophysical time series, J. R. Astron. Soc., 72, 647-664, 1983.

Samson, J. C., Greenwald, R. A., Ruohoniemi, J. M., and Baker, K. B.: High-frequency radar observations of atmospheric gravity waves in the high latitude ionosphere, Geophys. Res. Lett., 16, 875-878, 1989.

Samson, J. C., Greenwald, R. A., Ruohoniemi, J. M., Frey, A., and Baker, K. B. J.: Goose Bay radar observations of Earth-reflected atmospheric gravity waves in the high-latitude ionosphere, J. Geophys. Res., 95, 7693-7709, 1990.

Saunders, M. A., Freeman, M. P., Southwood, D. J., Cowley, S. W. H., Lockwood, M., Samson, J. C., Farrugia, C. J., and Hughes, T. J.: Dayside ionospheric convection changes in response to longperiod interplanetary magnetic field oscillations: Determination of the ionospheric phase velocity, J. Geophys. Res., 97, 1937319380, 1992.

Sibeck, D. G., Takahashi, K., Kokubun, S., Mukai, T., Ogilvie, K. W., and Szabo, A.: A case study of oppositely propagating Alfvénic fluctuations in the solar wind and magnetosheath, Geophys. Res. Lett., 24, 3133-3136, 1997.

Smith, C. W., Acuña, M. H., Burlaga, L. F., L’Heureux, J., Ness, N. F., and Scheifele, J.: The ACE Magnetic Field Experiment, Space Science Reviews, 86, 613-632, 1998.

Smith, M. F. and Lockwood, M.: The pulsating cusp, Geophys. Res. Lett., 17, 1069-1072, 1990.

Sofko, G. J. and Huang, C. S.: SuperDARN observations of medium-scale gravity wave pairs generated by Joule heating in 
the auroral zone, Geophys. Res. Lett, 27, 485-488, 2000.

Stauning, P., Friis-Christensen, E., Rasmussen, O., and Vennerstrøm, S.: Progressing polar convection disturbances: Signature of an open magnetosphere, J. Geophys., Res., 99, 11 303-11 317, 1994.

Stephenson, J. A. E. and Walker, A. D. M.: HF radar observations of Pc5 ULF pulsations driven by the solar wind, Geophys. Res. Lett., 29 (9), 10.1029/2001GL014291, 2002.

Stocker, A. J., Arnold, N. F., and Jones, T. B.: The synthesis of travelling ionospheric disturbances (TID) signatures in HF radar observations using ray tracing, Ann. Geophys., 18, 56-64, 2000,

\section{SRef-ID: 1432-0576/ag/2000-18-56.}

Stone, E. C., Frandsen, A. M., Mewaldt, R. A., Christian, E. R., Margolies, D., Ormes, J. F., and Snow, F.: The Advanced Composition Explorer, Space Sci. Rev., 86, 1-22, 1998.

Testud, J.: Gravity waves generated during magnetic substorms, J. Atmos. Terr. Phys., 32, 1793-1805, 1970.

Tsurutani, B. T. and Gonzalez, W. D.: The cause of high intensity long-duration continuous AE activity (HILDCAAs): Interplanetary Alfvén wave trains, Planet. Space Sci., 35, 405-412, 1987.

Tsurutani, B. T., Gould, T., Goldstein, B. E., Gonzalez, W. D., and Sugiura, M.: Interplanetary Alfvén waves and auroral (substorm) activity: IMP-8, J. Geophys. Res., 95, 2241-2252, 1990.

Tveten, L. H.: Ionospheric motions observed with high-frequency backscatter sounders, J. of Research of the National Bureau of Standards, D. Radio Propagation, 65D, 115-127, 1961.
Viljanen, A. and Häkkinen, L.: IMAGE magnetometer network, in Satellite-ground based coordination sourcebook, Eds. M. Lockwood, Wild, M. N., and Opgenoorth, H. J., ESA publications SP-1198, 111-117, 1997.

Waldock, J. A. and Jones, T. B.: Source regions of medium scale traveling ionospheric disturbances observed at mid-latitudes, J. Atmos. Terr. Phys., 49, 105-114,1987.

Walker, A. D. M.: Excitation of field line resonances by MHD waves originating in the solar wind, J. Geophys. Res., 107(A12), 1481, doi:10.1029/2001JA009188, 2002.

Williams, P. J. S., Lewis, R. V., Virdi, T. S., Lester, M., and Nielsen, E.: Plasma flow bursts in the auroral electrojets, Ann. Geophys., 10, 835-848, 1992.

Williams, P. J. S., Virdi, T. S., Lewis, R. V., Lester, M., Rodger, A. S., McCrea, I. W., and Freeman, K. S. C.: Worldwide atmospheric gravity-wave study in the European sector 1985-1990, J. Atmos. Terr. Phys., 55, 683-696, 1993.

Yan, M. and Lee, L. C.: Interaction of interplanetary shocks and rotational discontinuities with the Earth's bow shock, J. Geophys. Res., 101, 4835-4848, 1996.

Yeh, K. C. and Liu, C. H.: Acoustic-gravity waves in the upper atmosphere, Rev. Geophys. Space Phys., 12, 193-216, 1974. 